\title{
Monte-Carlo Based Laminar Flame Speed Correlation for Gasoline
}

\author{
Thesis by \\ Ahmed Ali Harbi \\ In Partial Fulfillment of the Requirements \\ For the Degree of \\ Master of Science
}

King Abdullah University of Science and Technology

Thuwal, Kingdom of Saudi Arabia

August, 2019 


\section{EXAMINATION COMMITTEE PAGE}

The thesis of Ahmed Ali Harbi is approved by the examination committee.

Committee Chairperson: Prof. Aamir Farooq

Committee Members: Prof. William Roberts, Prof. Hernando Ombao 
(C) August, 2019

Ahmed Ali Harbi

All Rights Reserved 


\section{ABSTRACT \\ Monte-Carlo Based Laminar Flame Speed Correlation for Gasoline}

Ahmed Ali Harbi

Gasoline is a complex fuel containing hundreds of species, and, therefore, it is quite difficult to model all components present in gasoline. Alternatively, researchers tend to employ simpler surrogates that mimic targeted physical and chemical properties of gasoline. Two properties of gasoline, i.e., autoignition and laminar flame speed, play key role in the overall performance of spark-ignition and modern engines. For fuel-engine optimization, it is very important to have simple models which can accurately predict autoignition and laminar flame speed of gasoline.

In this work, universal laminar flame speed correlation is proposed for typical gasolines. This correlation is based on Monte-Carlo simulations of randomly generated mixtures comprising of 21 gasoline-relevant molecules. Laminar flame speed of each molecule is numerically computed over a wide range of thermodynamic conditions using detailed chemical kinetic models, while flame speed of each mixture is estimated using a mixing rule. The proposed universal correlation is validated against experimentally-measured laminar flame speed of various gasoline fuels. 


\section{ACKNOWLEDGEMENTS}

I would like to express my gratitude to my advisor Prof. Aamir Farooq for his support, guidance and patience. I am thankful to the committee members Prof. William Roberts and Prof. Hernando Ombao for offering their valuable time. I am also thankful to my friends in KAUST and my colleagues in the Chemical Kinetics and Laser Sensors Laboratory.

My thesis is dedicated to my beloved family, Hisham, Sara, Omar, Majed, Adel, and my parents Hasna and Ali. 


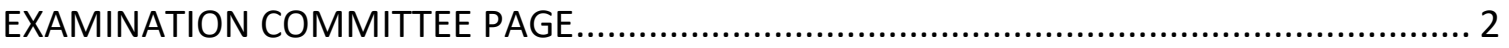

COPYRIGHT PAGE

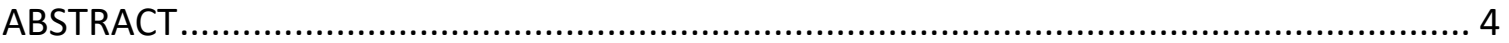

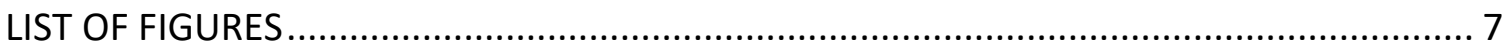

LIST OF TABLES

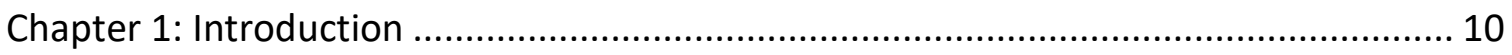

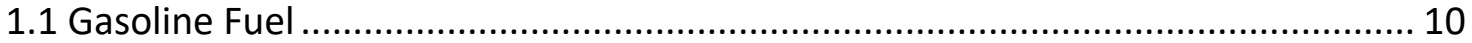

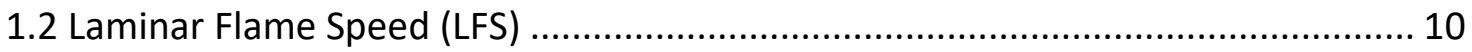

1.3 Literature Studies on Gasoline LFS Measurements ............................................ 13

1.4 Laminar Flame Speed Correlations .................................................................... 14

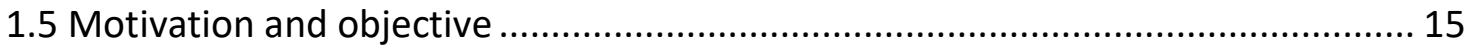

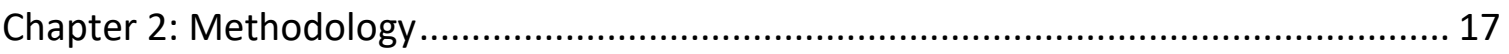

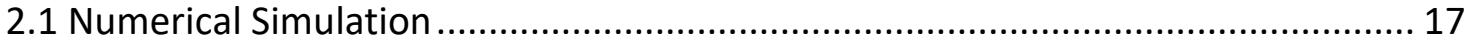

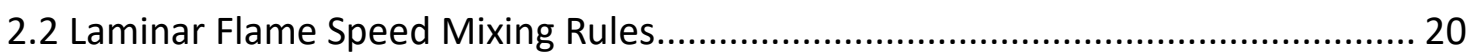

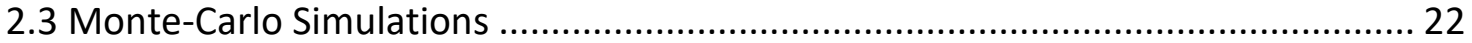

Chapter 3: Laminar Flame Speed Correlation............................................................... 25

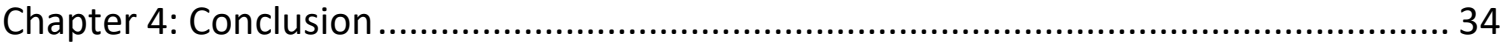

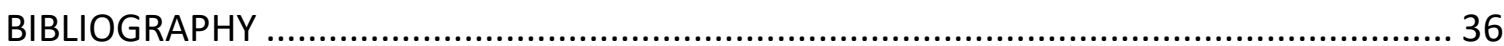

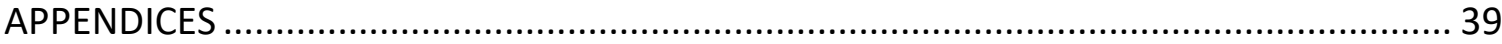

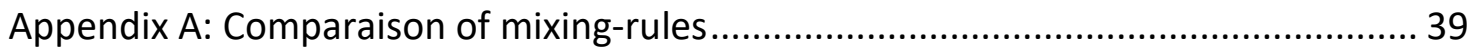

Appendix B: Composition of random mixtures ....................................................... 41

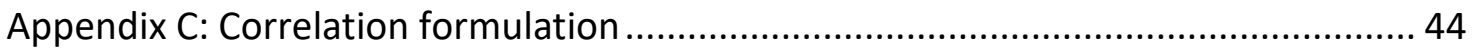




\section{LIST OF FIGURES}

Figure 1: Schematic of the premixed flame structure: (a) simple hydrodynamic model. (b) reaction sheet model. (c) complete structure. ..................................................... 12

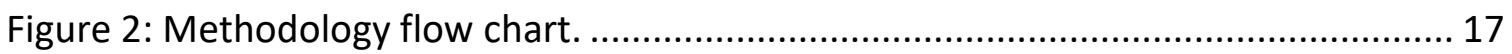

Figure 3: Summarized Chemkin-Pro/PREMIX code structure. ...................................... 19

Figure 4: Effect of the number of grid points on LFS and CPU time, computed for an equimolar mixture of 21 gasoline-related components at $300 \mathrm{~K}, 1 \mathrm{bar}$, and stoichiometry.

Figure 5: PDF comparison of laminar flame speed computed by mixing rule, Eq. (10), and Chemkin-Pro for 913 random mixtures of 21 selected components at $400 \mathrm{~K}, 1$ bar and $\phi$ $=1.1$

Figure 6: An example of a uniformly distributed 1000 random mixtures of 3 components, generated using Equation (11). 23

Figure 7: Stability test of LFS mean values generated using Monte-Carlo simulation for a different number of random mixtures of 21 selected components at $400 \mathrm{~K}, 1$ bar and $\phi$

$=1.1$

Figure 8: (a) Computed LFS of gasoline relevant components at $300 \mathrm{~K}$ and 1 bar. (b)

Distribution of LFS, classified by hydrocarbon groups, at $400 \mathrm{~K}, 1$ bar and $\phi=1.1 \ldots \ldots .25$

Figure 9: (a) PDF of LFS mixtures, (b) Mode, median, along with the first and third quartiles for varying number of components at $400 \mathrm{~K}, 1$ bar and $\phi=1.1$.

Figure 10: (a) LFS of constrained and unconstrained Monte-Carlo simulation against experimental data, at 1 bar. (b) PDF of constrained and unconstrained Monte-Carlo simulation at $400 \mathrm{~K}, 1 \mathrm{bar}$, and $\phi=1.1$.

Figure 11: Comparison between the predicted and expected LFS values, on the left using Equation (1), and on the right using Equation (16), green lines are $\pm 5 \mathrm{~cm} / \mathrm{s}$. 29

Figure 12: Residual analysis of the correlated LFS vs. the expected simulation LFS fitted by a normal distribution. 30

Figure 13: Comparison of proposed correlation against gasoline experimental LFS data at a range of initial temperatures.

Figure 14: Comparison of proposed correlation against gasoline experimental LFS data at a range of initial pressures.

Figure 15: Comparison of our correlation with high-pressures experimental data of Jerzembeck et al. [10].

Figure 16: Comparison between predicted LFS, using Eq. (16), and experimental LFS. The green lines are $\pm 10 \%$ deviations. 32 
Figure 17: LFS correlation for Exxon gasoline, obtained by applying $40 \%$ iso-octane and $30 \%$ toluene constraint on Monte-Carlo simulations.

Figure 18: LFS correlation formed by obtaining S0 for specific gasolines. (a) Exxon gasoline. (b) FACE-C gasoline. 34

Figure 19: Comparison between the LFS of equimolar mixtures obtained using ChemkinPro, and the different mixing rules at 1 bar and different temperatures. 39 Figure 20: Comparison between the LFS of equimolar mixtures obtained using ChemkinPro, and the different mixing rules at $500 \mathrm{~K}$ and different pressures............................ 40 Figure 21: Mole fraction PDFs of each component for 1000 random mixtures.............. 41

Figure 22: Constrained aromatics group to be higher than 30 mol\%. .......................... 42

Figure 23: Constrained alkenes group to be less than 6 mol\%. ...................................... 42

Figure 24: Temperature exponent assuming linear dependence. ................................. 44

Figure 25: Pressure exponent assuming linear dependence........................................ 45

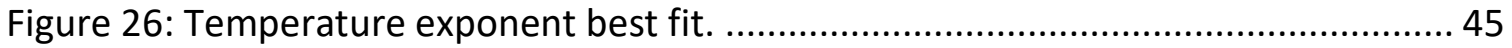

Figure 27: Pressure exponent best fit.................................................................. 46

Figure 28: Predicted LFS by Eq. (1) against the expected LFS, green lines are $\pm 5 \mathrm{~cm} / \mathrm{s} . .46$

Figure 29: Pressure exponent at different reference temperatures............................... 47

Figure 30: Predicted LFS against the expected LFS, green lines are $\pm 5 \mathrm{~cm} / \mathrm{s}$............... 47

Figure 31: Temperature exponents, assuming non-linear dependence. ....................... 48

Figure 32: Pressure exponents, assuming non-linear dependence............................... 48

Figure 33: Best fit for the Laminar flame speed at the reference conditions $300 \mathrm{~K}$ and 40

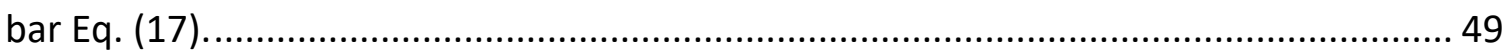

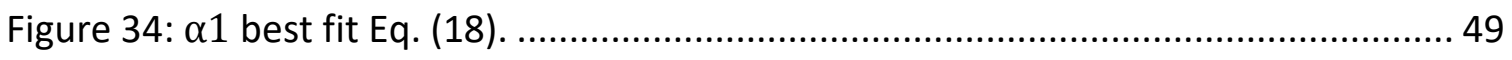

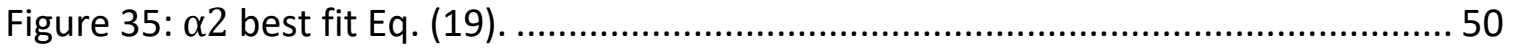

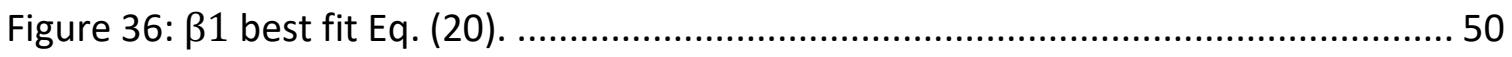

Figure 37: $\beta 2$ best fit Eq. (21)............................................................................... 51

Figure 38: Comparison between the predicted and expected LFS values the green lines are $\pm 2 \mathrm{~cm} / \mathrm{s}$. 


\section{LIST OF TABLES}

Table 1: Gasoline composition of literature experimental studies. ................................. 14

Table 2: Selected gasoline-related 21 components....................................................... 18

Table 3: Lower heating values (LHV) of the considered components. ........................... 21

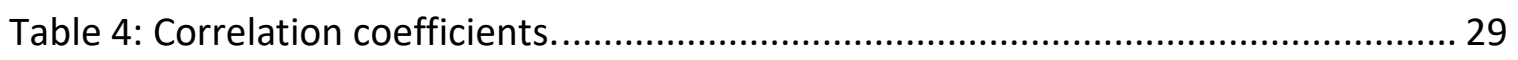

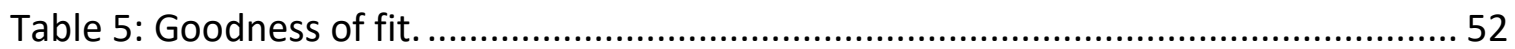




\section{Chapter 1: Introduction}

\subsection{Gasoline Fuel}

Gasoline is a multi-component liquid fuel containing hundreds of organic compounds, produced by crude oil distillation [1]. It is the most widely used transportation fuel where the transportation sector accounts for more than $20 \%$ of the world's energy consumption [2]. The increase of transportation energy demand caused by economic development and increasingly stringent emission regulations have been driving combustion and engine research towards a cleaner and more efficient solutions [3]. Gasoline is typically used in spark-ignition reciprocating internal combustion engines, where the fuel/air mixture is compressed and spark-ignited to form a propagating flame front [4]. Recently, gasoline has been investigated in advanced internal combustion concepts, such as partially premixed combustion PPC [5] , and gasoline direct injection GDI [6] where laminar flame speed is an important property characterizing the premixed combustion [7].

\subsection{Laminar Flame Speed (LFS)}

Laminar flame speed (LFS) is a physicochemical property that can be defined as the rate at which a free flame propagates towards unburned fuel/air mixture in a one-dimensional space [8]. LFS varies with the thermodynamic conditions of the unburned mixture, namely

pressure, temperature and equivalence ratio. The dependence of LFS on pressure is negative while temperature enhances the fuel reactivity. LFS is strongly dependent on equivalence ratio with a noticeable peak around stoichiometry for most hydrocarbon fuels. Laminar flame speed is also termed 'burning velocity'. 
Law [9] has classified the descriptions of the premixed flame structure into three levels of complexity. The simplest model in Fig. 1(a) considers the flame as a sheet separating the burnt and the unburnt gases which are in thermodynamic equilibrium. The temperature changes rapidly, with a strong discontinuity, from the temperature of the unburnt reactants to the temperature of the burnt products. The model is governed by the conservation of mass, species and energy, but it does not account for the transport properties and chemistry.

A more advanced model in Fig. 1(b) accounts for the transport properties by considering a preheat zone that has a characteristic thickness which is governed by mass and heat diffusion processes. The temperature profile changes gradually from the unburnt gas temperature through the preheat zone and then the reaction is activated and completed rapidly at a temperature close to the burnt gas temperature.

The third model is a complete structure in Fig. 1(c), known as the thermal theory of Zeldovich, Frank-Kamenetsky and Semenov, which accounts for the reaction rate that has a characteristic thickness affected by both the reaction activation and the depletion of the reactants. Hence, the premixed flame structure has two different zones, the preheat zone where convection and diffusion balance, and the reaction zone in which diffusion and reaction balance. 


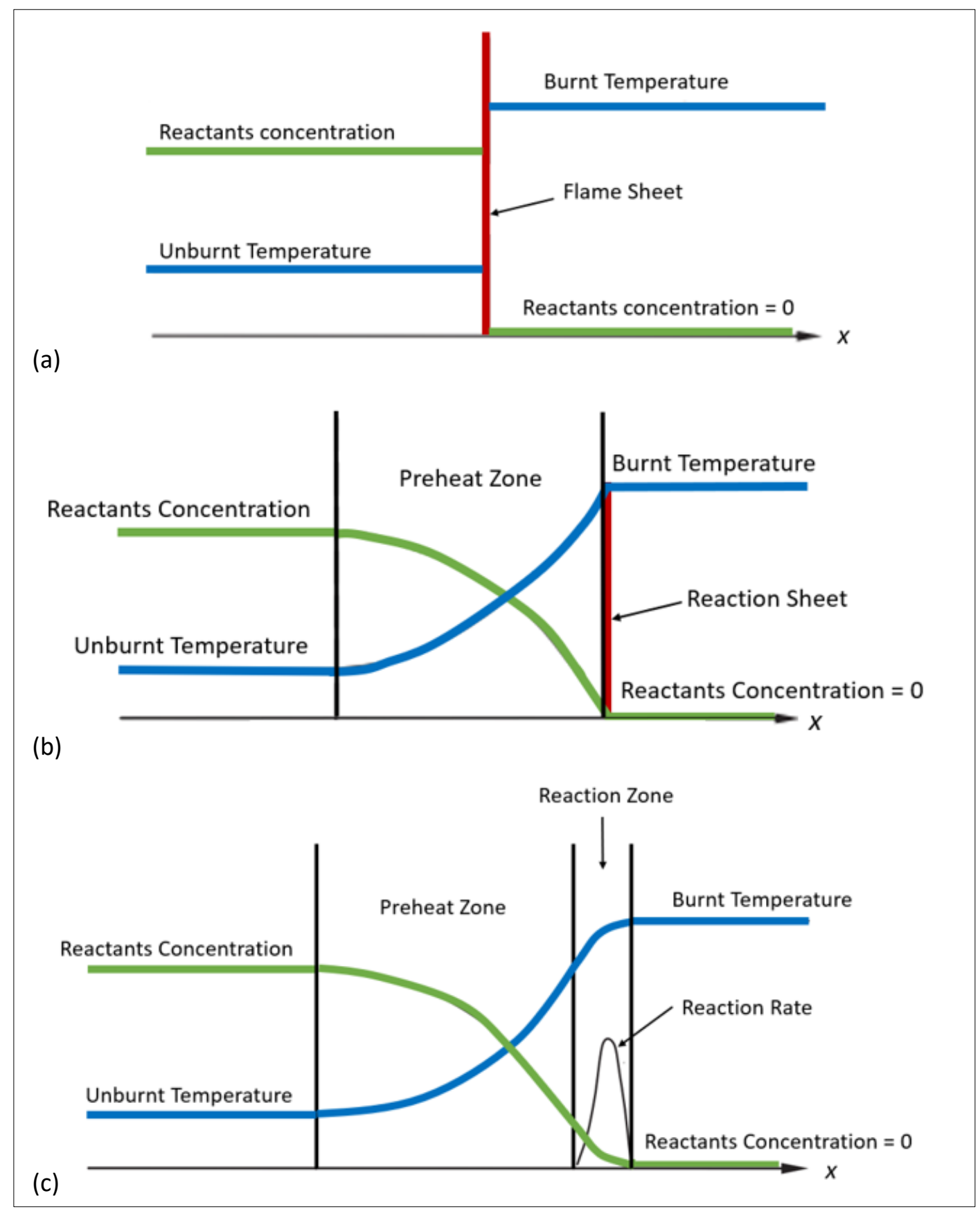

Figure 1: Schematic of the premixed flame structure: (a) simple hydrodynamic model. (b) reaction sheet model. (c) complete structure. 


\subsection{Literature Studies on Gasoline LFS Measurements}

Limited experimental laminar flame speed measurements have been reported for commercial gasoline due to experimental difficulties. Zhao et al. [10] measured gasoline LFS at $353 \mathrm{~K}$ and $500 \mathrm{~K}$, and atmospheric pressure over a wide range of equivalence ratios using a stagnation jet-wall configuration. High-pressure gasoline LFS has been measured by Jerzembeck et al. [11] at $373 \mathrm{~K}$ and pressures range from 10 bar up to 25 bar using constant volume method. Gasoline LFS temperature dependence was experimentally measured by Sileghem et al. [12] at atmospheric pressure and temperatures between 298 $\mathrm{K}$ and $358 \mathrm{~K}$ using the heat flux method. Dirrenberger et al. [13] also utilized the heat flux method to study the effect of ethanol addition to gasoline. Recently, Di Lorenzo et al. [14] reported European gasoline LFS measurements that contain 5\% ethanol at temperatures ranging from $373 \mathrm{~K}$ to $473 \mathrm{~K}$ and pressures from 1 to 5 bar.

Several gasoline surrogates and research fuels have been investigated in the literature. Huang et al. [15] performed LFS experiments on primary reference fuel (PRF) blends with research octane number RON ranging from 85 to 95 at room temperature and pressure. In a wider range of conditions, Liao et al. [16] has also measured LFS for PRFs and toluene reference fuel (TRFs) in addition to specified surrogates at atmospheric pressure and temperatures up to $400 \mathrm{~K}$. PRFs are binary mixtures of $n$-heptane and iso-octane whereas TRFs are ternary mixtures of toluene, $\mathrm{n}$-heptane and iso-octane. Mannaa et al. [17] investigated the pressure dependence of FACE-C gasoline at $358 \mathrm{~K}$ and pressures ranging from 1 bar to 6 bar. The composition of gasoline fuels used in literature experimental works is summarized in Table 1. 
Table 1: Gasoline composition of literature experimental studies.

\begin{tabular}{llccccc}
\hline Reference & Fuel & $\begin{array}{c}\text { n-alkanes } \\
\text { (vol\%) }\end{array}$ & $\begin{array}{c}\text { Alkenes } \\
\text { (vol\%) }\end{array}$ & $\begin{array}{c}\text { iso-alkanes } \\
\text { (vol\%) }\end{array}$ & $\begin{array}{c}\text { Aromatics } \\
\text { (vol\%) }\end{array}$ & $\begin{array}{c}\text { Oxygenates } \\
\text { (vol\%) }\end{array}$ \\
\hline Di Lorenzo et al. [14] & European Gasoline & $>3.6$ & 6.2 & -- & 33.7 & 5 \\
Zhao et al. [10] & CR-87 Gasoline & -- & -- & -- & -- & -- \\
Jerzembeck et al. [11] & Gasoline (RON 90) & The relative concentration of each component is less than 2\% \\
Sileghem et al. [12] & Exxon 708629-60 & 10.37 & 6.2 & 40.2 & 34.39 & 0 \\
Dirrenberger et al. [13] & TAE7000 & 10.5 & -- & 40.6 & 32.5 & -- \\
Huang et al. [15] & PRFs & $15,10,5$ & 0 & $85,90,95$ & 0 & 0 \\
Liao et al. [16] & Surrogate A & 17 & -- & 77.4 & 5 & 0 \\
Mannaa et al. [17] & FACE-C (mol\%) & 30 & 0.03 & 65.6 & 3.98 & 0 \\
\hline
\end{tabular}

\subsection{Laminar Flame Speed Correlations}

Laminar flame speed correlations are mathematical equations describing the LFS dependence on pressure, temperature and equivalence ratio. They have been used in engine simulations and computational fluid dynamics (CFD) codes for their simplicity and low computational expense. The most widely used form of LFS correlations is the powerlaw formulation Eq. (1). It is an empirical equation based on experimental observations of the laminar flame speed dependence on temperature, pressure and equivalence ratio.

$$
S(T, P, \phi)=S_{0}\left(\frac{T}{T_{0}}\right)^{\alpha}\left(\frac{P}{P_{0}}\right)^{\beta}
$$

where $S$ is the laminar flame speed as a function of temperature $T$, pressure $P$, and equivalence ratio $\phi$ while $S_{0}$ represents the LFS at reference conditions $T_{0}$ and $P_{0}$. The temperature exponent $\alpha$ varies with equivalence ratio and has positive values while $\beta$ represents the LFS pressure dependence and has negative values. In 1982, Metghalchi and Keck [18] had investigated the simple power-low correlation along with an Arrhenius 
correlation form based on the thermal theory of Zeldovich, Frank-Kamenetsky and Semenov. They found that both correlations equally reproduce the experimental results of different fuels namely, methanol, propane, iso-octane and two gasoline research fuels in a wide range of thermodynamic conditions. However, the empirical power-law correlation, Eq. (1), is recommended by the authors for its considerable simplicity and its good agreement with the experimental data, and since then, it is the most frequently used laminar flame speed correlation.

Different formulations for $S_{0}, \alpha$ and $\beta$ have been proposed in the literature. The most frequently used correlation formulation presented in equations (2-4) was proposed by Heywood [4] based on gasoline research fuel experiments . Recently, Amirante et al. [19] proposed a gasoline correlation by performing non-linear regression fitting algorithm on a wide range of commercial gasoline LFS experimental data. Several other authors have proposed numerically based correlations for specific gasoline surrogates [20]-[22].

$$
\begin{gathered}
S_{0}=30.5-5.49(\phi-1.21)^{2} \\
\alpha=2.4-0.271 \phi^{3.51} \\
\beta=-0.357+0.14 \phi^{2.77}
\end{gathered}
$$

\subsection{Motivation and objective}

In order to model a gasoline fuel comprising of hundreds of components, researchers tend to employ simpler formulations that mimic targeted gasoline properties. Such formulations are called surrogates and may comprise of two components or more, such as primary reference fuels (PRFs) and toluene reference fuels (TRFs) [23]. In an alternative 
approach, Xu et al. [24] recently showed that if the number of components of a fuel mixture (e.g., jet fuel or gasoline) exceeded a critical value ( $14-18)$, the hightemperature combustion behavior becomes statistically identical regardless of the exact composition. This conclusion was based on studying 100 randomly generated mixtures of 18 components related to jet fuel.

The objective of this thesis is to investigate the applicability of Xu et al. [24] principle on gasoline, and to formulate a universal laminar flame speed correlation based on MonteCarlo simulations of a large number of gasoline related components. 


\section{Chapter 2: Methodology}

The methodology follows an iterative process, as shown in Fig. 2. We start by generating a laminar flame speed database for 21 gasoline-relevant components (see Table 2). Thereafter, LFS is calculated for randomly generated mixtures using a suitable mixing rule. An LFS correlation is then formed and validated initially against Monte-Carlo simulations and then against experimentally-measured LFS of various gasoline fuels. Finally, gasoline laminar flame speed correlation is proposed. The details of each step are discussed in the following sections.

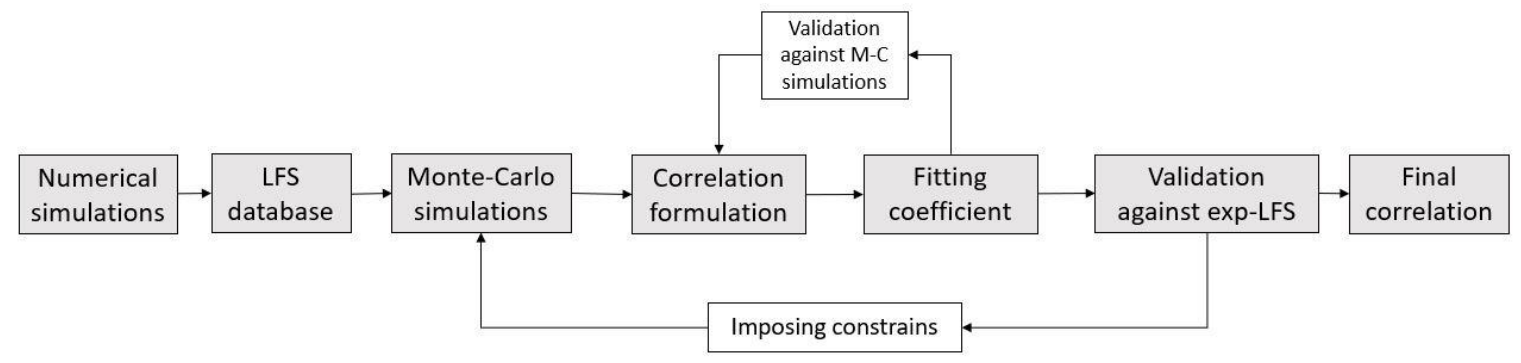

Figure 2: Methodology flow chart.

\subsection{Numerical Simulation}

Initially, 21 gasoline related components are selected based on detailed hydrocarbon analysis of different commercial gasolines and the availability of chemical kinetic models of these components. The selected components belong to eight different functional groups, as listed in Table 2. 
Table 2: Selected gasoline-related 21 components.

\begin{tabular}{l|llll}
\hline Group & \multicolumn{4}{c}{ Components } \\
\hline n-alkanes & n-butane & n-heptane & n-pentane & n-decane \\
iso-alkanes & iso-octane & iso-butane & neopentane \\
Aromatics & benzene & toluene & xylenes & naphthalene \\
Cycloalkanes & cyclohexane & & \\
Cycloalkenes & cyclopentene & & \\
alkenes & butene & pentene & heptane & hexene \\
iso-alkenes & iso-butene & iso-octenes & \\
Oxygenates & methanol & ethanol & \\
\hline
\end{tabular}

Ranzi et al. [25] have developed a detailed chemical model for hydrocarbon and oxygenated fuels with particular emphasis on predicting laminar flame speeds. The model consists of 451 species and 17848 reactions. It is adopted in this work due to its wide range of validations against LFS experimental data.

One-dimensional adiabatic freely propagating laminar flame simulations are carried out using the PREMIX code in ANSYS Chemkin-Pro package [26], which links the chemical kinetic model and transport data to the PREMIX code, as shown Fig. 3. The code numerically solves related governing equations and returns an output file to Chemkin-Pro post-processer. 


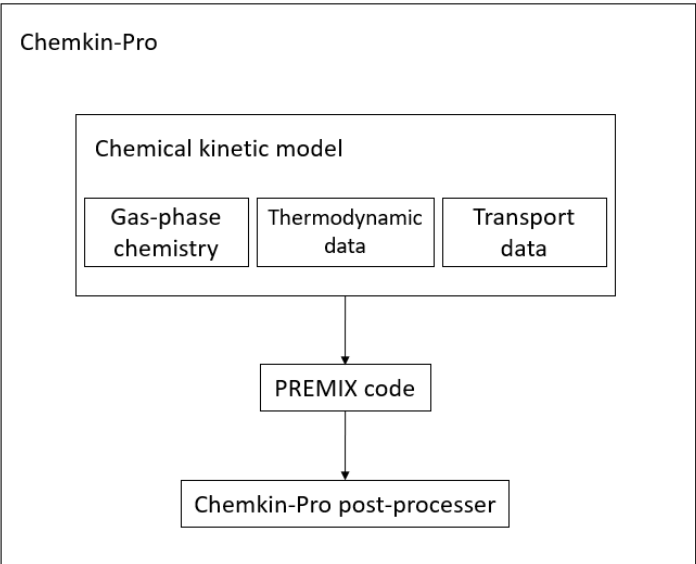

Figure 3: Summarized Chemkin-Pro/PREMIX code structure.

Laminar flame speed simulations are carried out for 21 pure components over a wide range of thermodynamic conditions; temperatures ranging from 300 to $600 \mathrm{~K}$ with $50 \mathrm{~K}$ step size, and pressures of 1, 5, 10, 15, 20 and 40 bar, and equivalence ratios of 0.6 to 1.7 with 0.1 step size. The adaptive grid parameters were set to 0.01 GRAD and 0.05 CURV to achieve approximately 1500 grid points while accounting for thermal diffusion effect. Figure 4 shows the effect of grid points on LFS and the corresponding computational expenses.

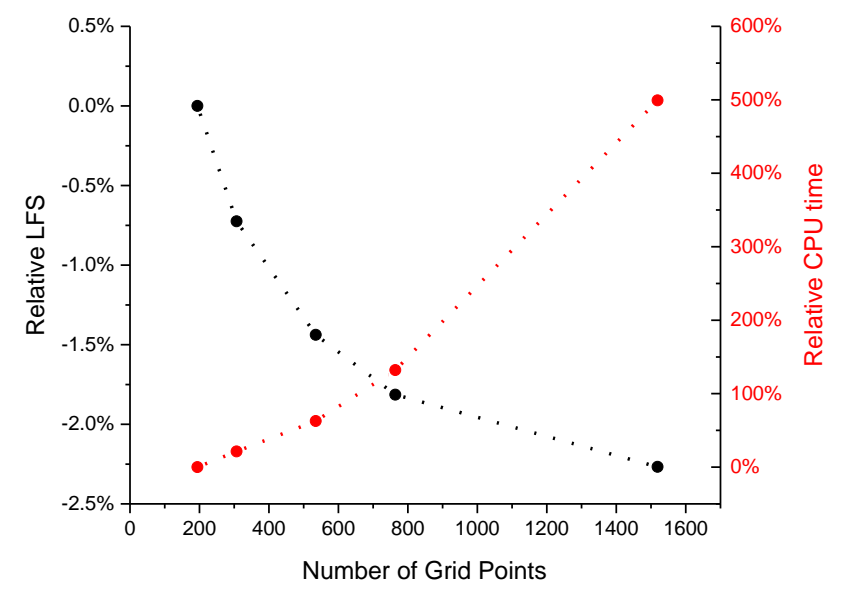

Figure 4: Effect of the number of grid points on LFS and CPU time, computed for an equimolar mixture of 21 gasoline-related components at $300 \mathrm{~K}, 1$ bar, and stoichiometry. 


\subsection{Laminar Flame Speed Mixing Rules}

It is not feasible to numerically compute the laminar flame speed of thousands of randomly generated mixtures at each thermodynamic condition. However, mixing rules can be utilized to estimate the LFS of a mixture based on the LFS of each individual component. A number of mixing rules are available in the literature and are listed here:

$$
\begin{gathered}
S_{\text {mixture }}=\sum_{i=1}^{n} x_{i} S_{\text {comp }, i} \\
S_{\text {mixture }}=\sum_{i=1}^{n} \omega_{i} S_{\text {comp }, i} \\
S_{\text {mixture }}=\sum_{i=1}^{n} \gamma_{i} S_{\text {comp }, i} \\
\gamma_{i}=\frac{x_{i} L H V_{i}}{\sum_{i=1}^{n} x_{i} L H V_{i}} \\
S_{\text {mixture }}=\frac{1}{\sum_{i=1}^{n} \frac{x_{i}}{S_{\text {comp }, i}}} \\
S_{\text {mixture }}=\frac{1}{\sum_{i=1}^{n} \frac{\gamma_{i}}{S_{\text {comp }, i}}}
\end{gathered}
$$

where, $x_{i}$ is the mole fraction, $\omega_{i}$ is the mass fraction, $\gamma_{i}$ is the energy fraction, and $L H V_{i}$ is the lower heating value (given in Table 3 for our selected components).

Sileghem et al. [27] investigated different mixing rules for mixtures of limited number of components and found that energy fraction based Le Chatelier's mixing rule, Eq. (10), provided the most accurate results. In this work, we also tested various mixing rules and 
agreed with Sileghem et al. [27] conclusion. Figure 5 compares LFS probability density function, for 913 random mixtures of 21 components, computed using Eq. (10) and Chemkin-Pro. The difference between the two peaks is negligibly small, $0.6356 \mathrm{~cm} / \mathrm{s}$, which shows that Le Chatelier's mixing rule does a good job of predicting LFS of fuel mixtures. Additional comparisons among other mixing rules are shown in Appendix A.

Table 3: Lower heating values (LHV) of the considered components.

\begin{tabular}{lccc}
\hline Component & MW $(\mathbf{g} / \mathbf{m o l})$ & $\Delta_{\boldsymbol{f}} \boldsymbol{H}_{\boldsymbol{c}}^{\mathbf{0}}$ (kJ/mol) [28] & LHV (kJ/mol) \\
\hline n-butane & 58.1222 & -125.6 & 2657.59 \\
n-heptane & 100.2019 & -187.8 & 4501.41 \\
n-pentane & 72.1488 & -146.8 & 3271.73 \\
n-decane & 142.2817 & -301 & 6294.23 \\
iso-octane & 114.2285 & -259.3 & 5065.25 \\
iso-butane & 58.1222 & -134.2 & 2648.99 \\
Neopentane & 72.1488 & -167.9 & 3250.63 \\
Benzene & 78.1118 & -82.9 & 3003.65 \\
Toluene & 92.1384 & -50.1 & 3671.79 \\
Xylenes & 106.165 & -19 & 4338.23 \\
Naphthalene & 128.1705 & -150 & 4752.42 \\
Cyclohexane & 84.1595 & -124.6 & 3687.44 \\
Cyclopentene & 68.117 & -36 & 2898.87 \\
1-butene & 56.1063 & -0.63 & 2540.73 \\
Pentenes & 70.1329 & -22 & 3154.7 \\
Heptenes & 98.1861 & -63 & 4384.38 \\
Hexene & 84.1595 & -42 & 3770.04 \\
iso-butene & 56.1063 & -17.9 & 2523.46 \\
iso-octenes & 112.2126 & -88.3 & 4994.42 \\
Methanol & 32.0419 & -205 & 672.17 \\
Ethanol & 46.0684 & -234 & 1278.51 \\
\hline
\end{tabular}




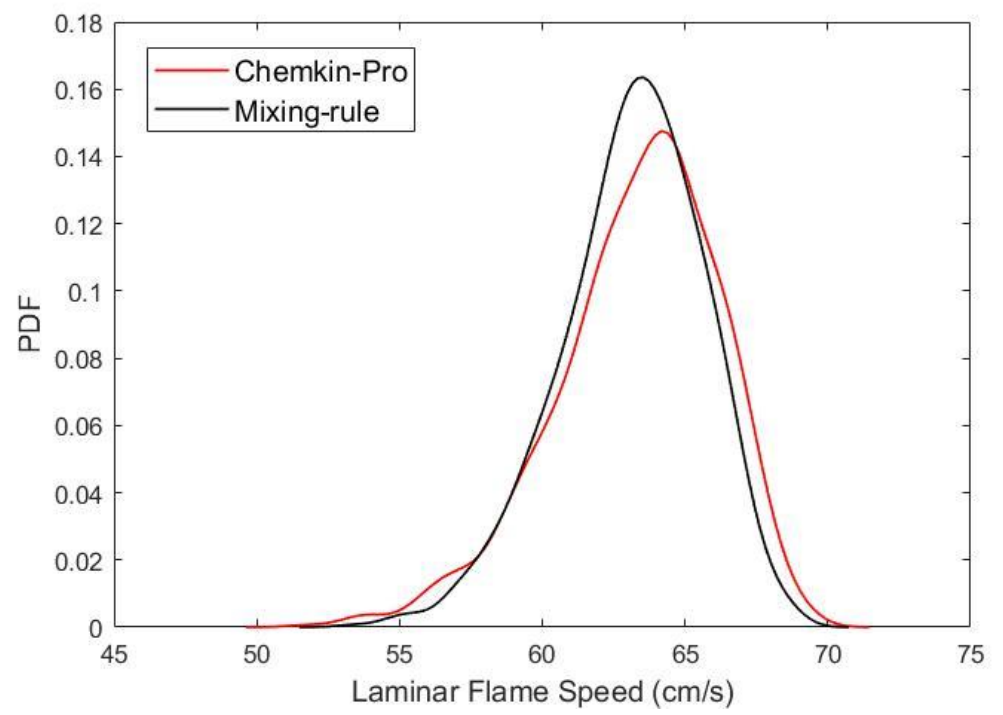

Figure 5: PDF comparison of laminar flame speed computed by mixing rule, Eq. (10), and Chemkin-Pro for 913 random mixtures of 21 selected components at $400 K, 1$ bar and $\phi=1.1$

\subsection{Monte-Carlo Simulations}

Monte-Carlo simulation is a statistical method used to estimate an outcome probability distribution from randomly sampled input variables. In this work, at each thermodynamic condition $(T, P$ and $\phi)$, the input is an $m \times n$ matrix of randomly generated mole fractions $M_{i, j}$ for $i=1,2, \ldots, m$ number of random mixtures of $j=1,2, \ldots, n$ number of components, while the output is the corresponding laminar flame speed $S_{m i x, i}$ of each mixture calculated using the energy fraction based Le Chatelier's mixing rule Eq. (10).

Each random mixture $i$ is physically constrained. It must have real positive values while satisfying the conditions $M_{i, j} \in(0,1)$ and $\sum_{j=1}^{n} M_{i, j}=1$. Furthermore, a large number of mixtures should be sampled until Monte-Carlo simulation results become sufficiently stable. The samples need to be uniformly distributed among the different components. In other words, each component must experience different mole fractions uniformly. 
Khaled [29] suggested that for such an application, $M_{i, j}$, uniformly distributed random samples, can be generated from a flat Dirichlet distribution in the form of a normalized gamma distribution,

$$
M_{i, j}=\frac{\Gamma\left(\alpha_{j}\right)}{\sum_{j=1}^{n} \Gamma\left(\alpha_{j}\right)}
$$

where the parameters $\alpha_{1}, \alpha_{1}, \ldots, \alpha_{n}$ are set to unity for a uniformly distributed sample. This distribution can be seen in Fig. 6 for an example of 1000 random mixtures of 3 components. Each point in the plot represents a random mixture that lies in a simplex constrained by the sum to unity.

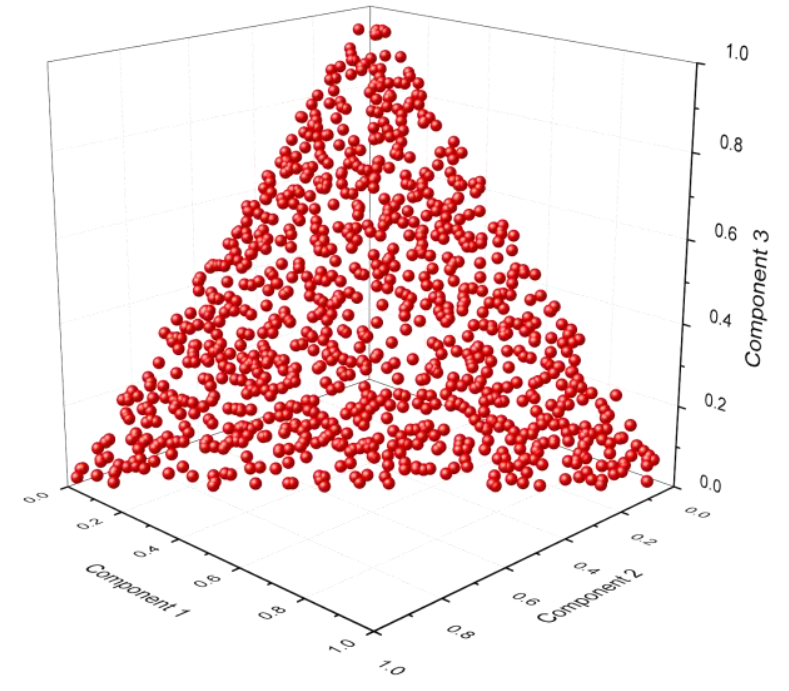

Figure 6: An example of a uniformly distributed 1000 random mixtures of 3 components, generated using Equation (11).

As a representative case, for Monte-Carlo simulation results at $400 \mathrm{~K}, 1$ bar and $\phi=1.1$ for random mixtures of 21 components, the mean of $S_{m i x, i}$ stabilizes after approximately 10,000 random mixtures. The difference in mean values becomes negligibly small, within 
$0.1 \mathrm{~cm} / \mathrm{s}$, as shown in Fig. 7, where the probability density function of $S_{\text {mix }, i}$ is estimated using kernel density estimator function in MATLAB.

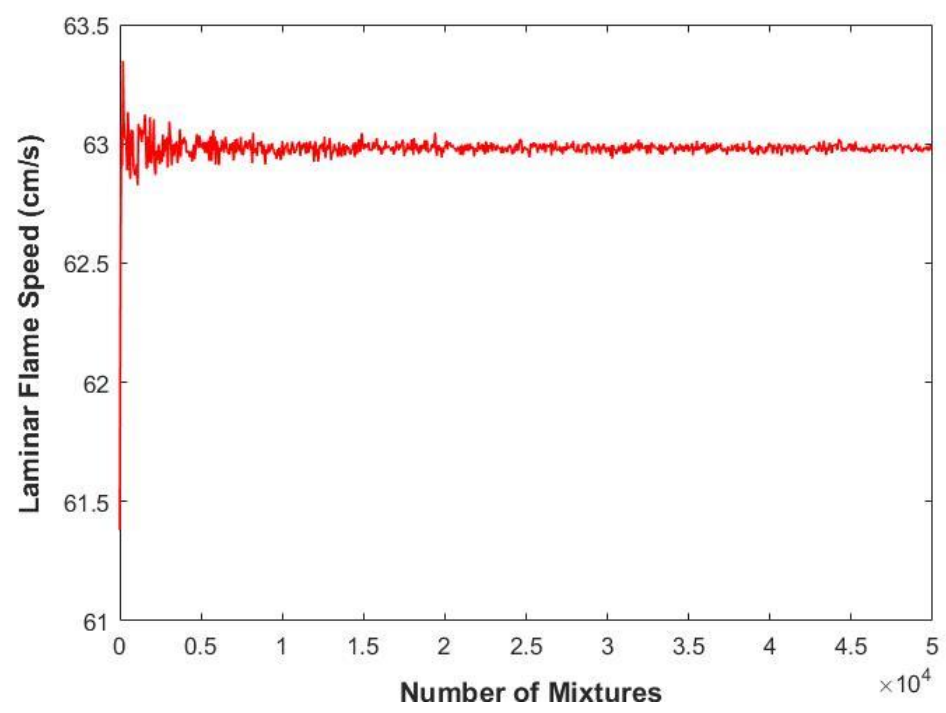

Figure 7: Stability test of LFS mean values generated using Monte-Carlo simulation for a different number of random mixtures of 21 selected components at $400 K, 1$ bar and $\phi=1.1$. 


\section{Chapter 3: Laminar Flame Speed Correlation}

Numerically computed laminar flame speeds are obtained for 21 components at 504 thermodynamic conditions (given in Section 2.1). Figure 8(a) shows the computed LFS of each component at $300 \mathrm{~K}$ and 1 bar. It can be noticed in Fig. 8(b) that alkenes and oxygenates are the most reactive components, while aromatics have relatively small LFS values. Methanol has a distinguishable dependence on the equivalence ratio as it is the most reactive component on the fuel-rich side. Methanol is expected to make relatively small effect on the overall LFS of a mixture because of its relatively small lower heating value.

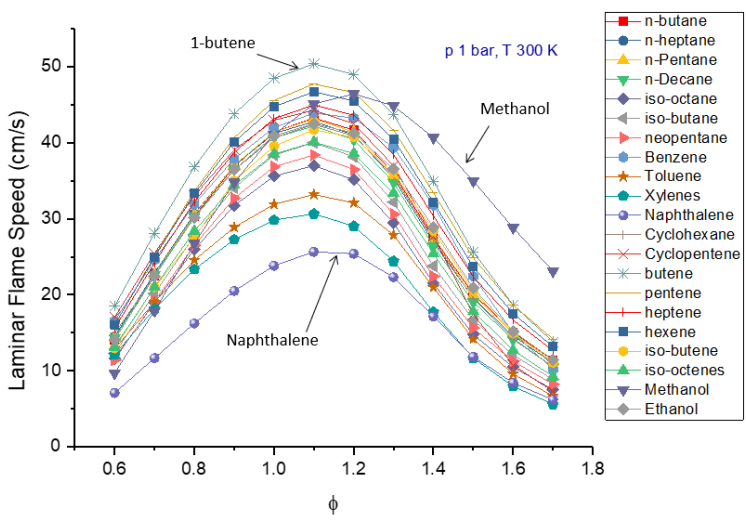

(a)

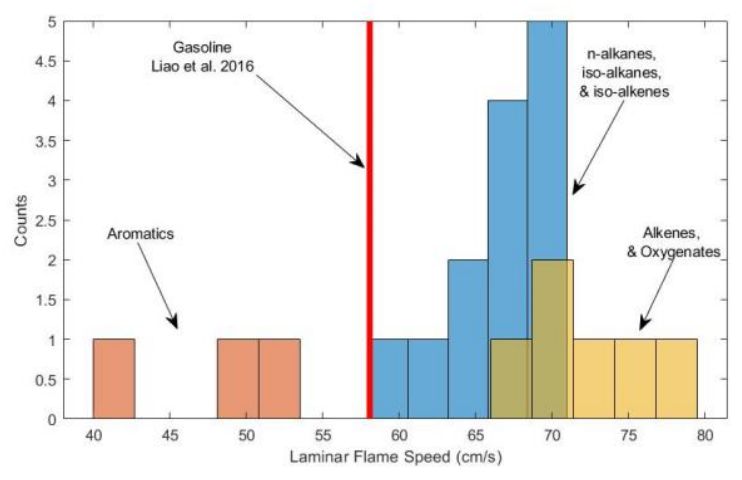

(b)

Figure 8: (a) Computed LFS of gasoline relevant components at $300 \mathrm{~K}$ and 1 bar. (b) Distribution of LFS, classified by hydrocarbon groups, at $400 \mathrm{~K}, 1$ bar and $\phi=1.1$.

Monte-Carlo simulations are carried out for varying number of components. As expected, the spread of the probability density function of $S_{\text {mix,i }}$ decreases as the number of components increases, as can be seen in Fig. 9(a). The spread of $S_{\text {mix, } i}$ of generated mixtures is shown in Fig. 9(b) for varying number of components, where we see that $50 \%$ 
of the results are within $3.4 \mathrm{~cm} / \mathrm{s}$ for 21 components. This analysis is in agreement with Xu et al. [24] hypothesis that the laminar flame speed converges to a unique value for large number of components.

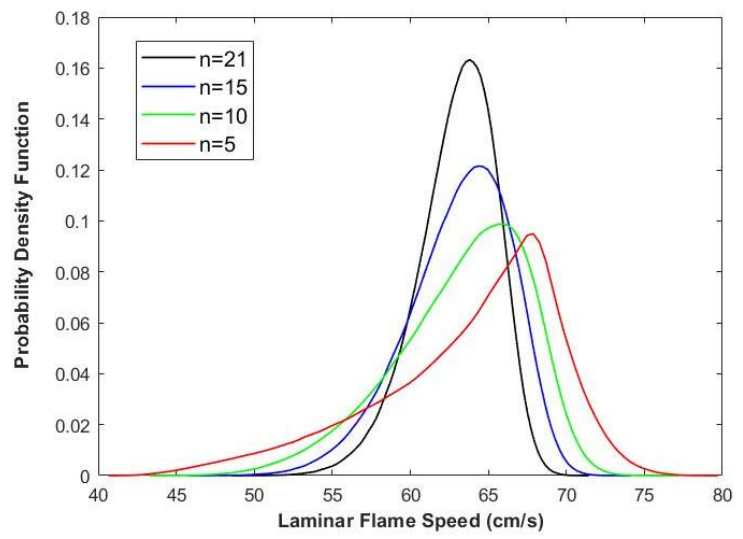

(a)

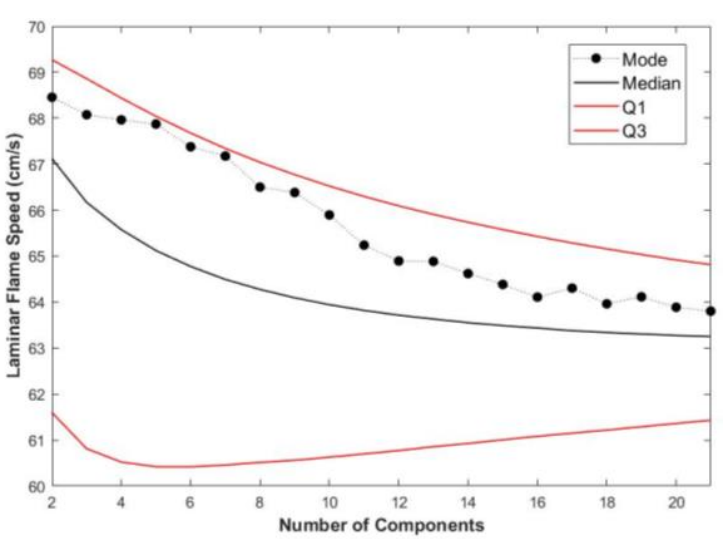

(b)

Figure 9: (a) PDF of LFS mixtures, (b) Mode, median, along with the first and third quartiles for varying number of components at $400 K, 1$ bar and $\phi=1.1$.

Next, we compared our computed flame speed with literature measurements of gasoline LFS. Figure 10(a) shows that Monte-Carlo simulations are slightly overestimating experimental gasoline results. This is caused by the extreme LFS values of aromatics and alkenes where Monte-Carlo simulations treat each component equally regardless of its LFS value. In order to improve the predictability of the model, reasonable constraints are imposed based on real gasoline composition. Commercial gasoline usually contains more than $30 \%$ aromatics and less than $5 \%$ alkenes. Examples of constrained random mixtures are shown in Appendix B. Applying these constraints resulted in a much better agreement with experimental LFS measurements. The spread of the LFS values also noticeably decreased in terms of Q3-Q1 from $3.4 \mathrm{~cm} / \mathrm{s}$ to $1.84 \mathrm{~cm} / \mathrm{s}$. The probability density functions 
of both constrained and unconstrained Monte-Carlo simulations are shown in Figure 10

(b) for 21 components.

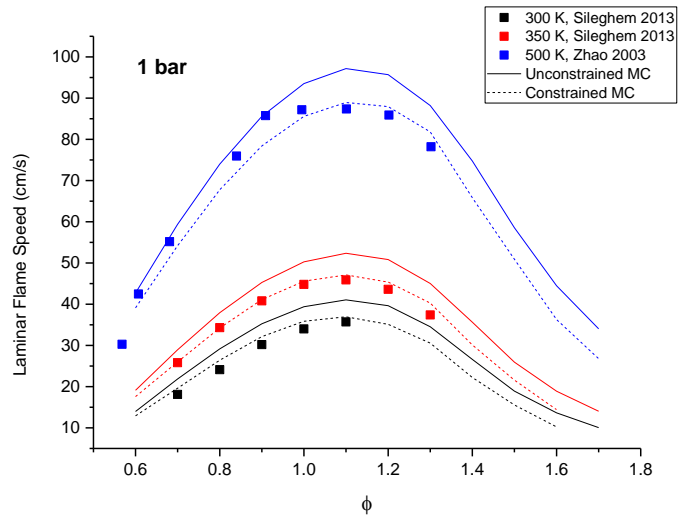

(a)

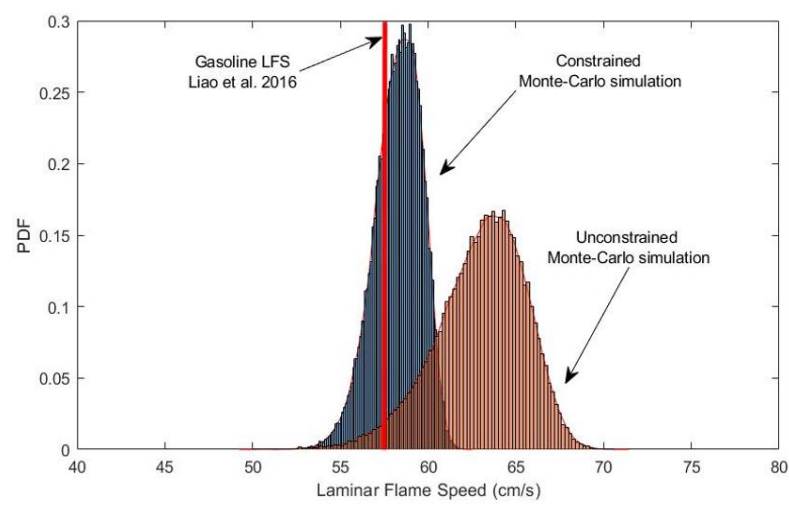

(b)

Figure 10: (a) LFS of constrained and unconstrained Monte-Carlo simulation against experimental data, at 1 bar. (b) PDF of constrained and unconstrained Monte-Carlo simulation at $400 \mathrm{~K}, 1 \mathrm{bar}$, and $\phi=1.1$.

The numerical LFS results and, therefore, Monte-Carlo simulations are obtained for discrete thermodynamic conditions. In order to interpolate the result and validate against experimental data, an empirical correlation is formed. Initially, the simple power-law Eq. (1) is considered. $S_{0}$ is obtained by the best fit of the flame speed at reference conditions $T_{0}=300 \mathrm{~K}$ and $P_{0}=1$ bar. The temperature exponent $\alpha$ is calculated by fitting a line for each value of $\phi$ in a $\log \left(S / S_{0}\right)$ vs $\log \left(T / T_{0}\right)$ plot, and the best fit is obtained for $\alpha$ as a function of $\phi$. Similarly, pressure exponent $\beta$ is obtained. However, $\beta$ is found to have a significant dependence on temperature along with $\phi$. Therefore, $\beta$ is calculated at each $\phi$ and $T$, and then a functional form is obtained by fitting a surface over these results.

The correlation obtained in this manner, i.e., using Eq. (1), reproduces the simulation results within $\pm 5 \mathrm{~cm} / \mathrm{s}$, as shown in Fig. 11 . The deviation is mainly caused by the 
assumption of linear dependence of $\log \left(S / S_{0}\right)$ on $\log \left(T / T_{0}\right)$ and $\log \left(P / P_{0}\right)$ while it is noticeably non-linear especially at rich conditions $(\phi>1.3)$. To better reproduce the simulation results, a new correlation is formed. It is based on the same power-law correlation but by assuming second-order polynomial dependence, as seen in Eqs. (1416).

$$
\begin{gathered}
\log \left(\frac{S(T, \phi)}{S_{0}}\right)=\alpha_{1} \log ^{2}\left(\frac{T}{T_{0}}\right)+\alpha_{2} \log \left(\frac{T}{T_{0}}\right) \\
\log \left(\frac{S(P, \phi)}{S_{0}}\right)=\beta_{1} \log ^{2}\left(\frac{P}{P_{0}}\right)+\beta_{2} \log \left(\frac{P}{P_{0}}\right) \\
S(T, P, \phi)=S_{0} \cdot\left(\frac{T}{T_{0}}\right)^{\alpha_{2}} \cdot e^{\left[\alpha_{1} \log ^{2}\left(\frac{T}{T_{0}}\right)\right]} \cdot\left(\frac{P}{P_{0}}\right)^{\beta_{2}} \cdot e^{\left[\beta_{1} \log ^{2}\left(\frac{P}{P_{0}}\right)\right]}
\end{gathered}
$$

The coefficients $\alpha_{1}, \alpha_{2}, \beta_{1}$ and $\beta_{2}$ are obtained by fitting second-order polynomials for each $\phi$ value from the normalized logarithmic dependence of $S$ on $T$ and for each $\phi$ and $T$ values from the normalized logarithmic dependence of $S$ on $P$. Thereafter, the best fit is obtained for each of $S_{0}(\phi), \alpha_{1}(\phi), \alpha_{2}(\phi), \beta_{1}(\phi, T)$, and $\beta_{2}(\phi, T)$ in the form of the following Eqs. (17-21) where the coefficients are given in Table 4. The fitting procedure is described in detail in Appendix C.

$$
\begin{gathered}
S_{0}(\phi)=s_{0}+s_{1} \phi+s_{2} \phi^{2}+s_{3} \phi^{3}+s_{4} \phi^{4}+s_{5} \phi^{5} \\
\alpha_{1}(\phi)=a_{11} e^{-\left(\frac{\phi-a_{12}}{a_{13}}\right)^{2}}+a_{14} e^{-\left(\frac{\phi-a_{15}}{a_{16}}\right)^{2}} \\
\alpha_{2}(\phi)=a_{21} e^{-\left(\frac{\phi-a_{22}}{a_{23}}\right)^{2}}+a_{24} e^{-\left(\frac{\phi-a_{25}}{a_{26}}\right)^{2}} \\
\beta_{1}(\phi, T)=b_{10}+b_{11} \phi+b_{12} T+b_{13} \phi^{2}+b_{14} \phi T+b_{15} \phi^{3}+ \\
b_{16} \phi^{2} T+b_{17} \phi^{4}+b_{18} \phi^{3} T
\end{gathered}
$$




$$
\begin{gathered}
\beta_{2}(\phi, T)=b_{20}+b_{21} \phi+b_{22} T+b_{23} \phi^{2}+b_{24} \phi T+b_{25} \phi^{3}+ \\
b_{26} \phi^{2} T+b_{27} \phi^{4}+b_{28} \phi^{3} T
\end{gathered}
$$

Table 4: Correlation coefficients.

\begin{tabular}{cccccc}
\hline $\boldsymbol{i}$ & $\boldsymbol{s}_{\boldsymbol{i}}$ & $\boldsymbol{a}_{\mathbf{1 , i}}$ & $\boldsymbol{a}_{\mathbf{2}, \boldsymbol{i}}$ & $\boldsymbol{b}_{\mathbf{1}, \boldsymbol{i}}$ & $\boldsymbol{b}_{\mathbf{2 , \boldsymbol { i }}}$ \\
\hline $\mathbf{0}$ & 49.97 & 0.4005 & 1.763 & -0.08916 & -2.72 \\
$\mathbf{1}$ & -259.2 & 1.705 & 1.744 & 0.5932 & 5.118 \\
$\mathbf{2}$ & 424.1 & 0.2217 & 0.5783 & 0.0009096 & 0.005697 \\
$\mathbf{3}$ & -89.07 & 5489 & 4.967 & -1.372 & -1.29 \\
$\mathbf{4}$ & -151.1 & -50.66 & -1.159 & 0.002722 & -0.01628 \\
$\mathbf{5}$ & 61.52 & 16.66 & 1.79 & 1.148 & -2.545 \\
$\mathbf{6}$ & & & & -0.002508 & 0.01509 \\
$\mathbf{7}$ & & & & -0.3019 & 1.186 \\
$\mathbf{8}$ & & & & 0.0007065 & -0.004429 \\
\hline
\end{tabular}
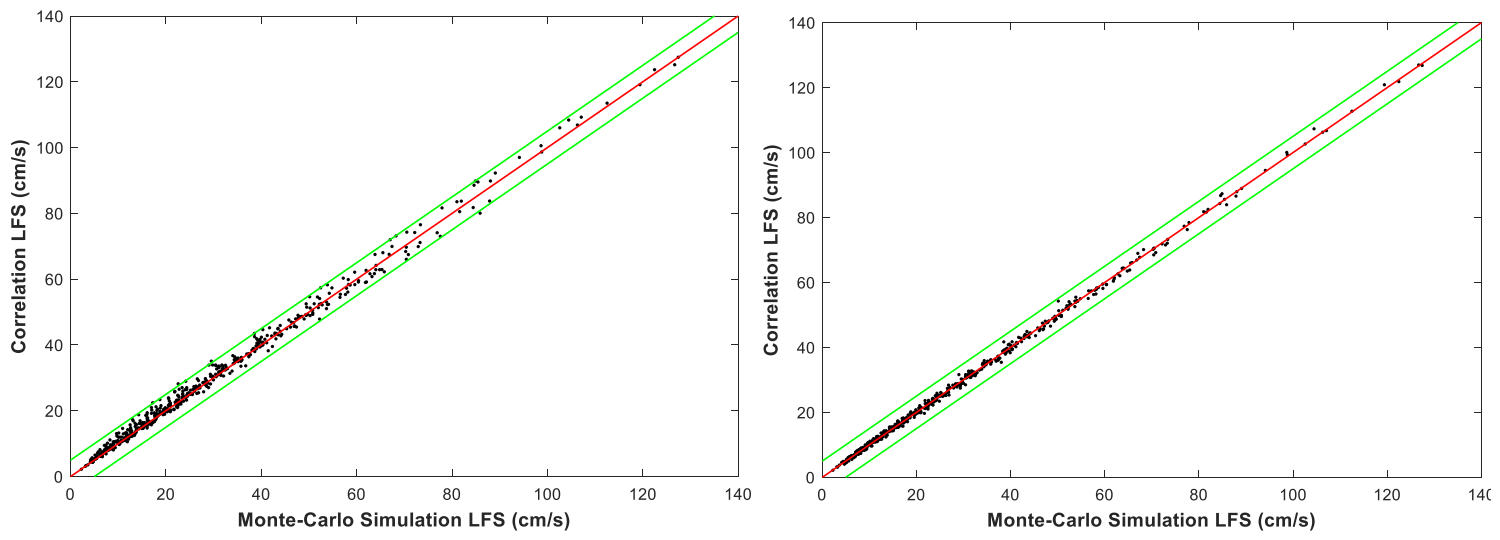

Figure 11: Comparison between the predicted and expected LFS values, on the left using Equation (1), and on the right using Equation (16), green lines are $\pm 5 \mathrm{~cm} / \mathrm{s}$.

The new correlation form reproduces the simulation results within $\pm 2 \mathrm{~cm} / \mathrm{s}$, as shown in the right panel of Fig. 11. The residuals are fitted to a normal distribution, as seen in Fig. 12. The mean of the residuals is statistically zero as the results fall within $\pm 1.6 \mathrm{~cm} / \mathrm{s}$ with 95\% confidence interval. 


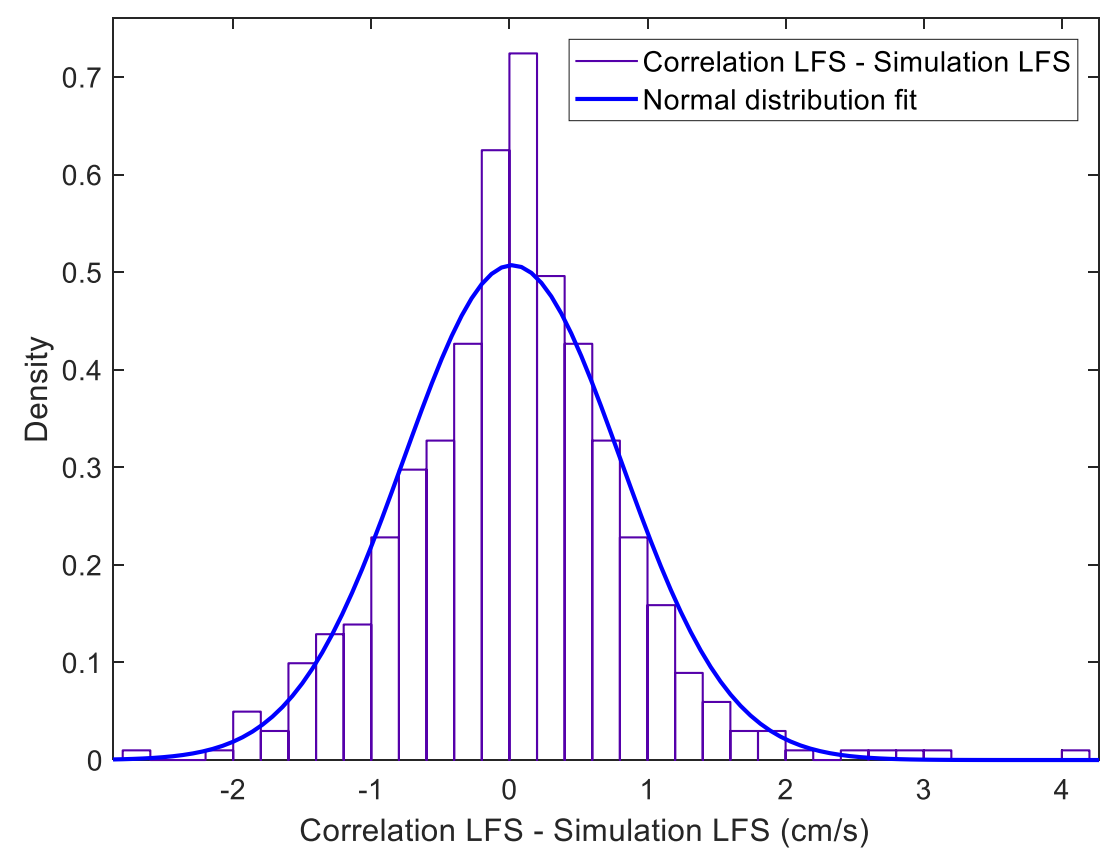

Figure 12: Residual analysis of the correlated LFS and the simulated LFS, fitted by a normal distribution.

The new correlation also does a good job of capturing the temperature dependence of experimental gasoline LFS data, as shown in Fig. 13 for temperatures ranging from $298 \mathrm{~K}$ to $500 \mathrm{~K}$. The pressure dependence is also well captured by the proposed correlation including high-pressure experimental results up to 25 bar, regardless of the gasoline composition, as can be seen in Figs. 14-15. The correlation overestimates Di Lorenze et al. [14] experimental results of a European gasoline at 1 bar and $473 \mathrm{~K}$ by $10 \%$ near stoichiometry. A nominal gasoline composition is provided by the authors (see Table 1) but detailed hydrocarbon analysis is needed to further investigate this deviation. Our proposed new correlation predicts all literature gasoline experimental data with $90 \%$ accuracy, as shown in Fig. 16. 

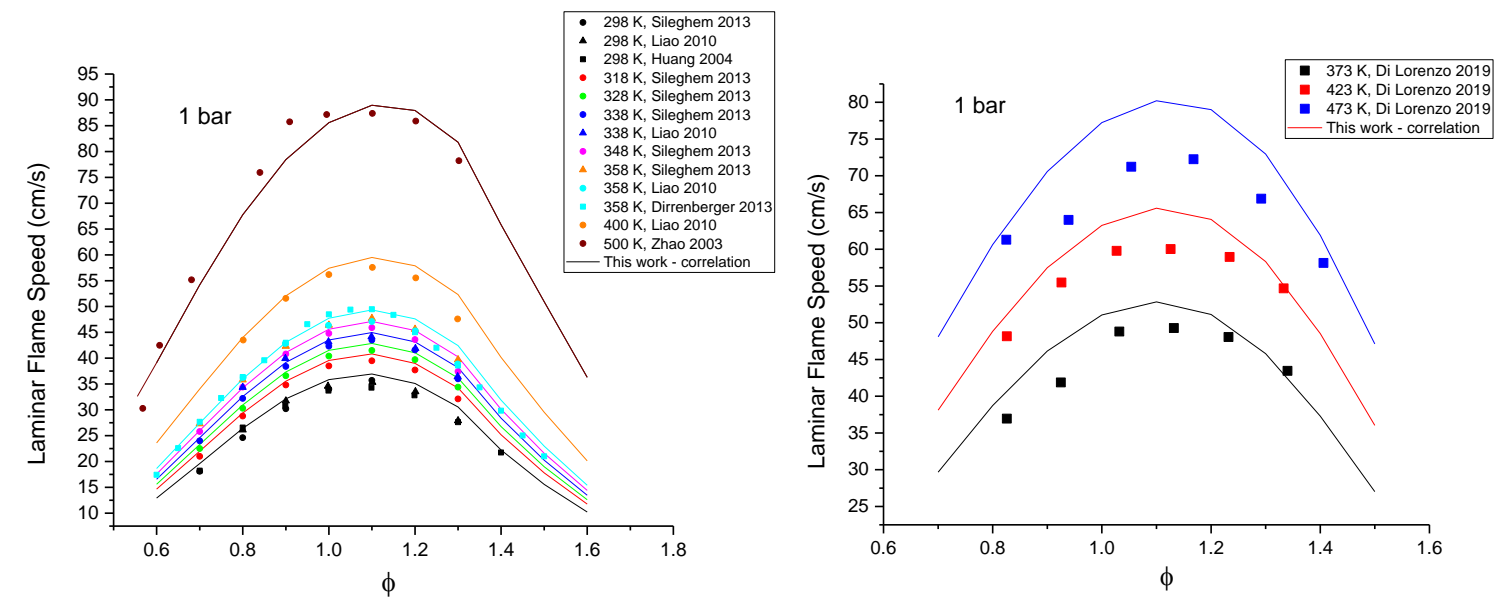

Figure 13: Comparison of proposed correlation against gasoline experimental LFS data at a range of initial temperatures.
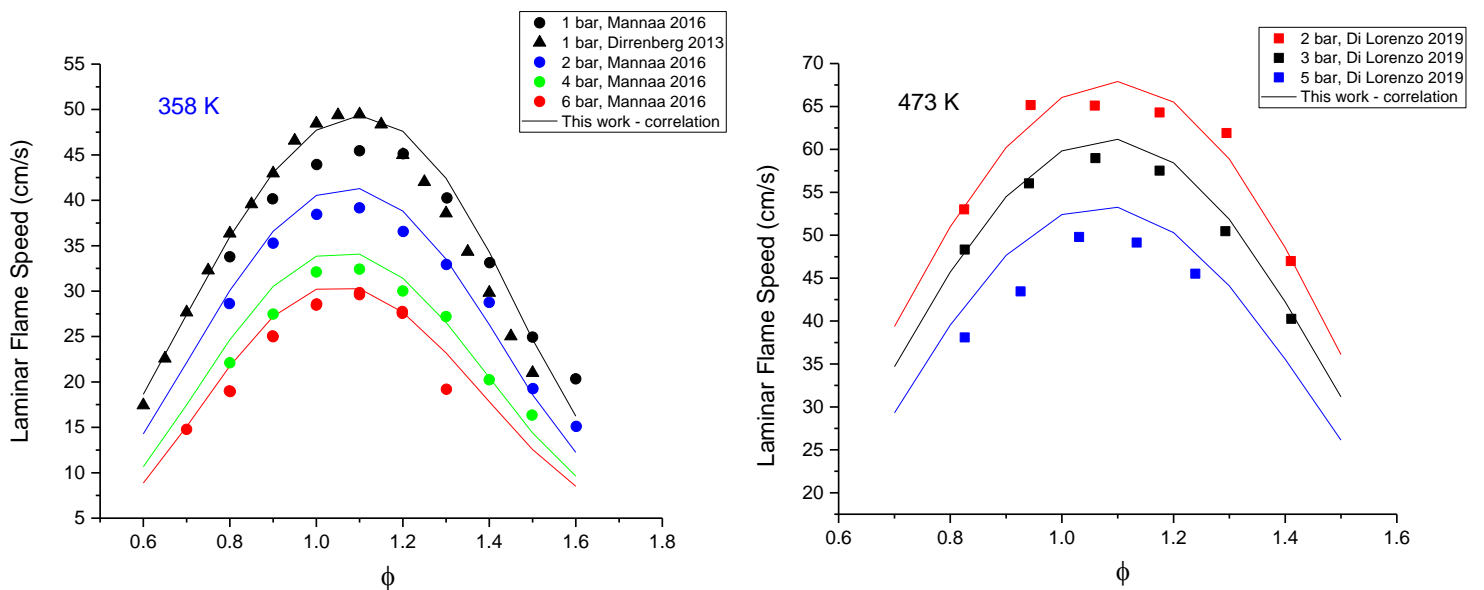

Figure 14: Comparison of proposed correlation against gasoline experimental LFS data at a range of initial pressures. 

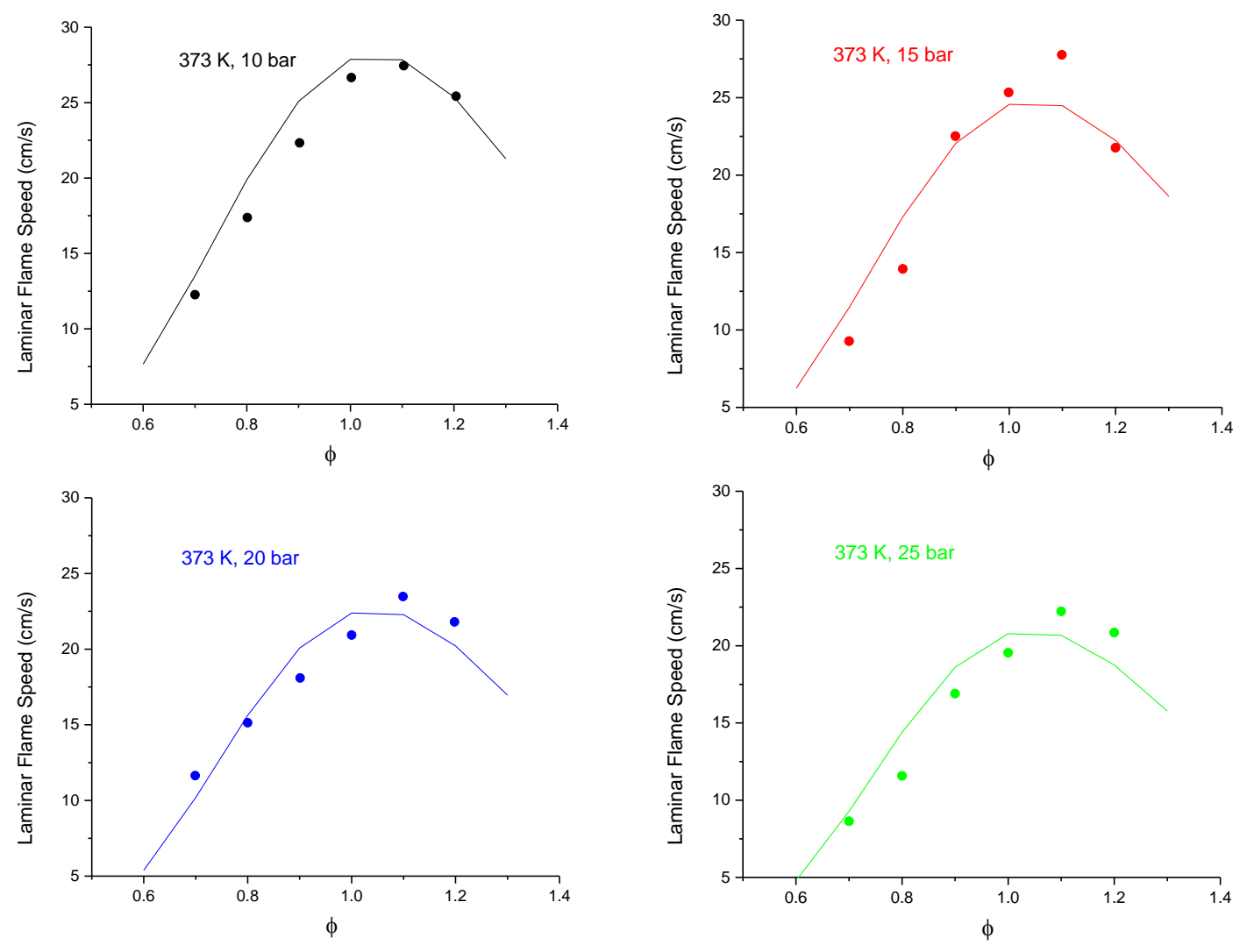

Figure 15: Comparison of our correlation with high-pressures experimental data of Jerzembeck et al. [10].

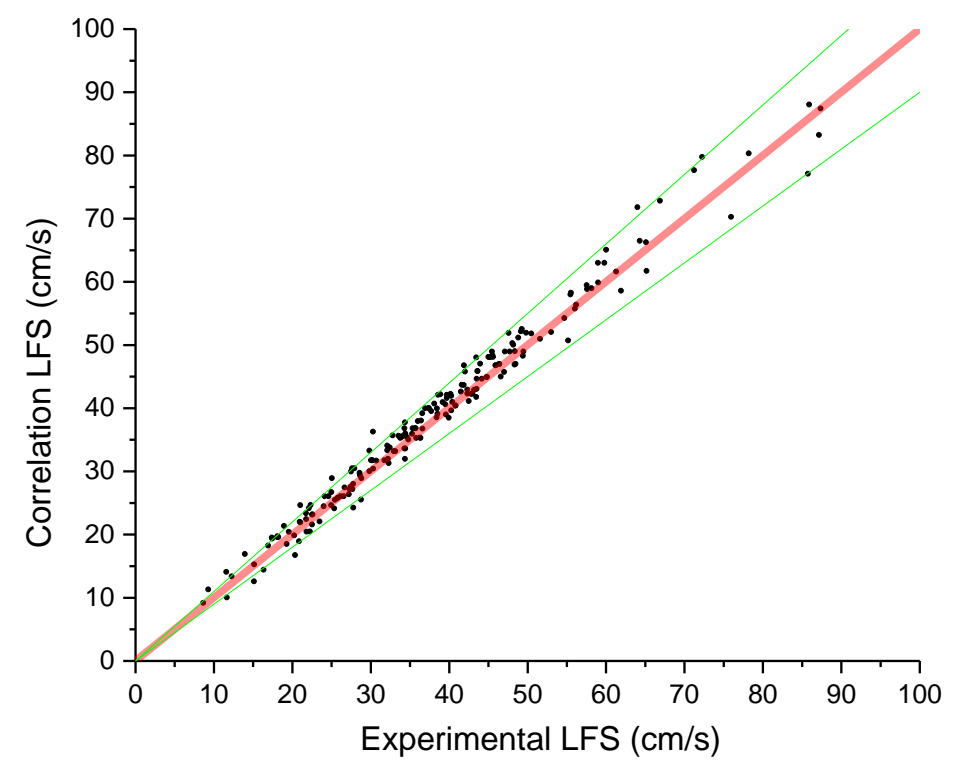

Figure 16: Comparison between predicted LFS, using Eq. (16), and experimental LFS. The green lines are $\pm 10 \%$ deviations. 
The proposed correlation captures all typical gasoline experimental data with high accuracy level. Furthermore, it can be utilized for specific gasoline by either imposing extra composition constraints on Monte-Carlo simulations or by simply providing the laminar flame speed at reference conditions $S_{0}$.

To illustrate the first scenario, we consider Sileghem [12] measurements of Exxon gasoline since the author has provided the detailed hydrocarbon analysis of the fuel. Constraining Monte-Carlo simulations to $40 \%$ iso-octane and $30 \%$ toluene resulted in a better agreement with the experimental results as shown in Fig. 17.

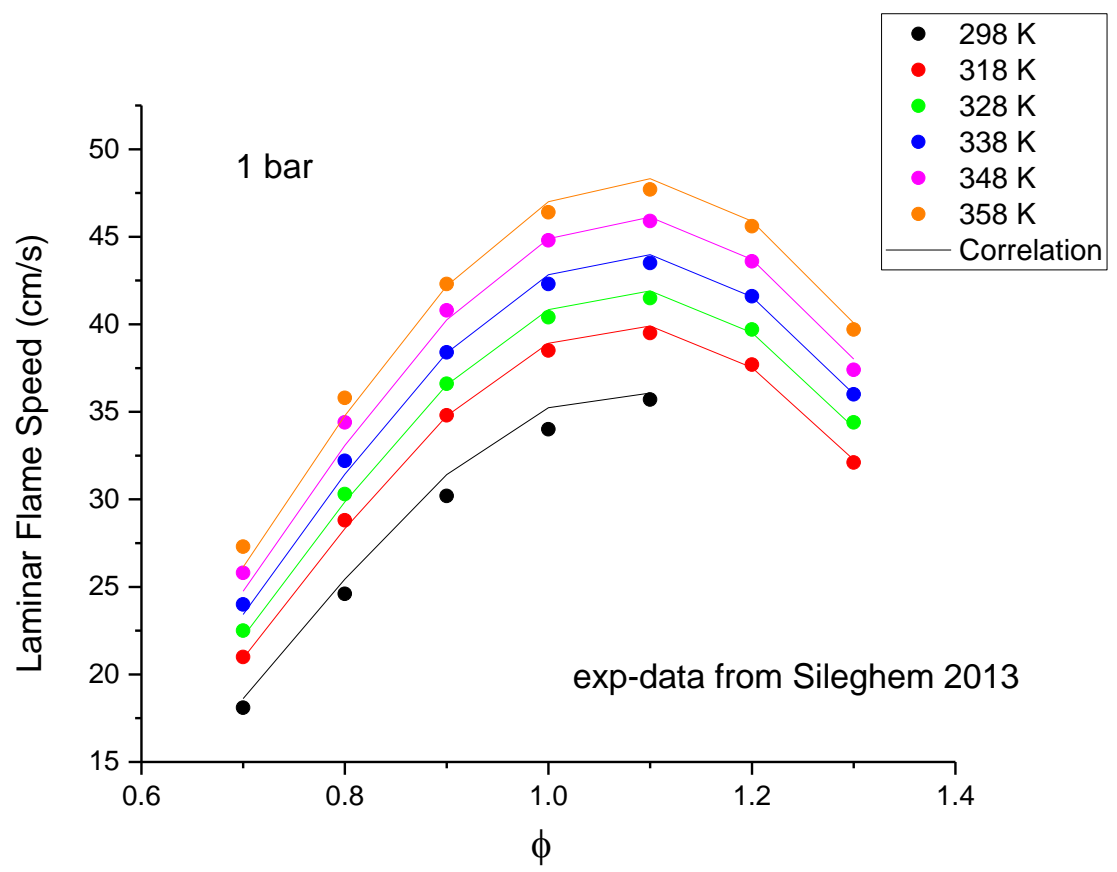

Figure 17: LFS correlation for Exxon gasoline, obtained by applying $40 \%$ iso-octane and $30 \%$ toluene constraint on Monte-Carlo simulations. 
Alternately, $S_{0}$ can be formulated for each individual gasoline while using the universal temperature and pressure dependence coefficients listed in Table 4. Figure. 18(a) shows the correlation results when $S_{0}$ is obtained by fitting a fifth order polynomial for Exxon gasoline LFS at reference conditions $P_{0}=1$ bar and $T_{0}=318 \mathrm{~K}$. Similarly, FACE-C gasoline correlation is formed by obtaining $S_{0}$ at $P_{0}=1$ bar and $T_{0}=358 \mathrm{~K}$ in Fig. $18(\mathrm{~b})$.

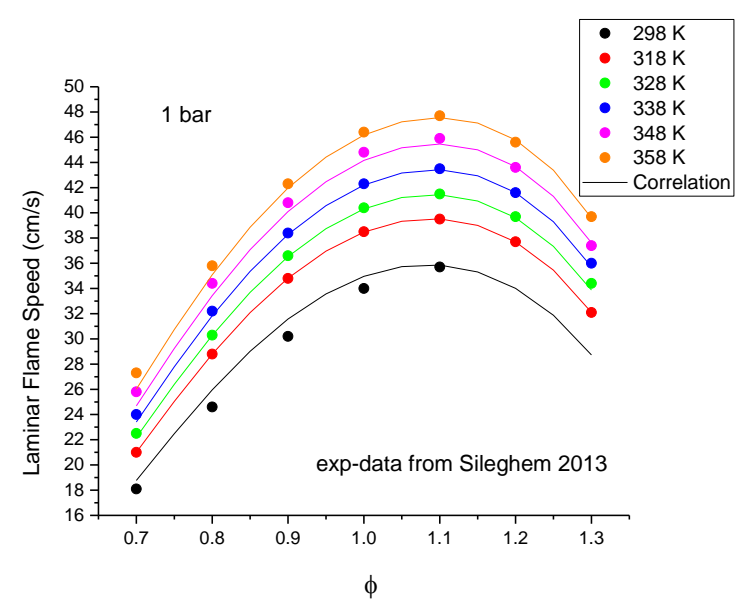

(a)

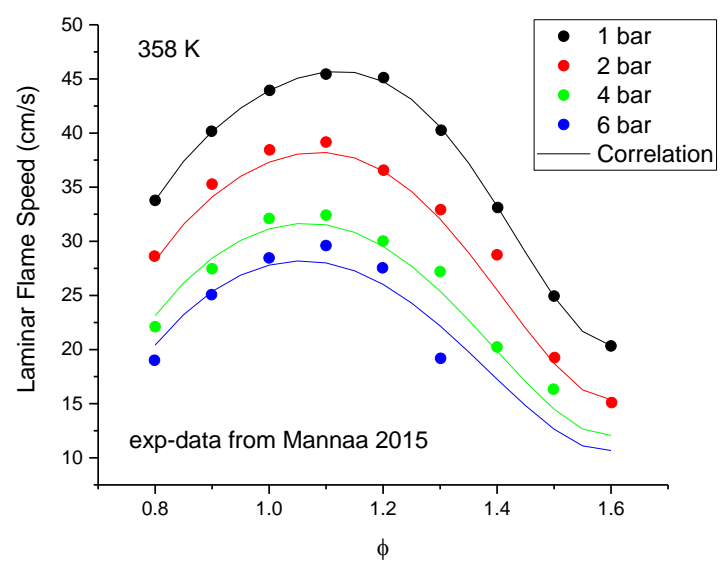

(b)

Figure 18: LFS correlation formed by obtaining $S_{0}$ for specific gasolines. (a) Exxon gasoline. (b) FACE-C gasoline. 


\section{Chapter 4: Conclusions}

We have proposed a universal Monte-Carlo based correlation to predict laminar flame speed of typical gasoline fuels. Various mixing rules for estimating LFS of a mixture are investigated and the energy-based Le Chatelier's mixing rule is found to have the highest accuracy.

Monte-Carlo simulations are performed for uniformly distributed random mixtures of 21 gasoline related components. Initial results overestimated gasoline laminar flame speed. However, applying realistic composition constraints improved the prediction ability and reduced the variance of the results. The final correlation is formulated in a way that captures the non-linearity observed in the normalized logarithmic flame speed dependence on pressure and temperature. It also accounts for the pressure exponent dependence on temperature along with equivalence ratio. The proposed formulation reproduces the simulated LFS values within $\pm 2 \mathrm{~cm} / \mathrm{s}$. The correlation captured experimental gasoline LFS data with greater than $90 \%$ accuracy. The proposed methodology is flexible to predict LFS for any gasoline by imposing specific constrains on the Monte-Carlo simulations. We believe that our methodology and proposed correlation will be highly valuable for engine optimization studies and CFD simulations. 


\section{BIBLIOGRAPHY}

[1] W. J. Pitz et al., "Development of an experimental database and chemical kinetic models for surrogate gasoline fuels," 2007.

[2] U.S. Energy Information Administration, International Energy Outlook 2016, vol. 0484(2016), no. May 2016. 2016.

[3] IEA, "2018 World Energy Outlook: Executive Summary,” Oecd/lea, p. 11, 2018.

[4] J. B. Heywood, "Internal combustion engine fundamentals ." McGraw-Hill , New York, 1988.

[5] V. Manente, B. Johansson, and W. Cannella, "Gasoline partially premixed combustion, the future of internal combustion engines?," Int. J. Engine Res., vol. 12, no. 3, pp. 194-208, 2011.

[6] U. Spicher, J. Reissing, J. M. Kech, and J. Gindele, "Gasoline Direct Injection (GDI) Engines - Development Potentialities," SAE Tech. Pap. Ser., vol. 1, no. 724, 2010.

[7] A. Lipatnikov and J. Chomiak, Premixed Turbulent Combustion, vol. 28. 2000.

[8] A. A. Konnov, A. Mohammad, V. R. Kishore, N. II Kim, C. Prathap, and S. Kumar, "A comprehensive review of measurements and data analysis of laminar burning velocities for various fuel+air mixtures," Prog. Energy Combust. Sci., vol. 68, pp. 197-267, 2018.

[9] C. K. Law, "LAMINAR PREMIXED FLAMES," in Combustion Physics, Cambridge: Cambridge University Press, 2006, pp. 234-302.

[10] Z. Zhao, J. P. Conley, A. Kazakov, and F. L. Dryer, "Burning Velocities of Real Gasoline Fuel at $353 \mathrm{~K}$ and 500 K," SAE Tech. Pap. Ser., vol. 1, no. 724, 2010.

[11] S. JERZEMBECK, N. PETERS, P. PEPIOTDESJARDINS, and H. PITSCH, "Laminar burning velocities at high pressure for primary reference fuels and gasoline: Experimental and numerical investigation," Combust. Flame, vol. 156, no. 2, pp. 292-301, Feb. 2009.

[12] L. Sileghem et al., "Laminar burning velocity of gasoline and the gasoline surrogate components iso-octane, n-heptane and toluene," Fuel, vol. 112, pp. 355-365, Oct. 2013.

[13] P. Dirrenberger et al., "Laminar burning velocity of gasolines with addition of ethanol," Fuel, vol. 115, pp. 162-169, Jan. 2014.

[14] M. Di Lorenzo, P. Brequigny, F. Foucher, and C. Mounaïm-Rousselle, "Validation of TRF-E as gasoline surrogate through an experimental laminar burning speed 
investigation," Fuel, vol. 253, pp. 1578-1588, Oct. 2019.

[15] Y. HUANG, C. SUNG, and J. ENG, "Laminar flame speeds of primary reference fuels and reformer gas mixtures," Combust. Flame, vol. 139, no. 3, pp. 239-251, Nov. 2004.

[16] Y.-H. Liao and W. L. Roberts, "Laminar Flame Speeds of Gasoline Surrogates Measured with the Flat Flame Method," Energy \& Fuels, vol. 30, no. 2, p. acs.energyfuels.5b01433, Feb. 2016.

[17] O. Mannaa, M. S. Mansour, W. L. Roberts, and S. H. Chung, "Laminar burning velocities at elevated pressures for gasoline and gasoline surrogates associated with RON," Combust. Flame, vol. 162, no. 6, pp. 2311-2321, Jun. 2015.

[18] M. Metghalchi and J. C. Keck, "Burning velocities of mixtures of air with methanol, isooctane, and indolene at high pressure and temperature," Combust. Flame, vol. 48, no. C, pp. 191-210, 1982.

[19] R. Amirante, E. Distaso, P. Tamburrano, and R. D. Reitz, "Laminar flame speed correlations for methane, ethane, propane and their mixtures, and natural gas and gasoline for spark-ignition engine simulations," Int. J. Engine Res., vol. 18, no. 9, pp. 951-970, Nov. 2017.

[20] M. Del Pecchia, S. Breda, A. D'Adamo, S. Fontanesi, A. Irimescu, and S. Merola, "Development of Chemistry-Based Laminar Flame Speed Correlation for PartLoad SI Conditions and Validation in a GDI Research Engine," SAE Int. J. Engines, vol. 11, no. 6, pp. 2018-01-0174, Apr. 2018.

[21] R. Hesse, J. Beeckmann, K. Wantz, and H. Pitsch, "Laminar Burning Velocity of Market Type Gasoline Surrogates as a Performance Indicator in Internal Combustion Engines," 2018, pp. 1-11.

[22] I. Z. Syed, Y. Yeliana, A. Mukherjee, J. Naber, and D. Michalek, "Numerical Investigation of Laminar Flame Speed of Gasoline - Ethanol/Air Mixtures with Varying Pressure, Temperature and Dilution," SAE Int. J. Engines, vol. 3, no. 1, pp. 517-528, 2010.

[23] S. M. Sarathy, A. Farooq, and G. T. Kalghatgi, "Recent progress in gasoline surrogate fuels," Prog. Energy Combust. Sci., vol. 65, pp. 67-108, 2018.

[24] R. Xu and H. Wang, "Principle of large component number in multicomponent fuel combustion - a Monte Carlo study," Proc. Combust. Inst., vol. 37, no. 1, pp. 613-620, 2019.

[25] E. Ranzi et al., "Hierarchical and comparative kinetic modeling of laminar flame speeds of hydrocarbon and oxygenated fuels," Prog. Energy Combust. Sci., vol. 38, no. 4, pp. 468-501, Aug. 2012. 
[26] "ANSYS Chemkin-Pro 19.1." ANSYS, 2018.

[27] L. Sileghem, J. Vancoillie, J. Demuynck, J. Galle, and S. Verhelst, "Alternative fuels for spark-ignition engines: Mixing rules for the laminar burning velocity of gasoline-alcohol blends," Energy and Fuels, vol. 26, no. 8, pp. 4721-4727, 2012.

[28] E. P.J. Linstrom and W.G. Mallard, NIST Chemistry WebBook, NIST Standard Reference Database Number 69. National Institute of Standards and Technology, Gaithersburg MD, 20899.

[29] F. KHALED, "Reactivity of Hydrocarbon Fuels: Reaction Kinetics and Ignition Delay Times." 2018. 


\section{APPENDICES}

\section{Appendix A: Comparaison of mixing rules}

The different mixing rules are investigated by comparison to Chemkin-Pro simulations for equimolar mixtures of 21 components. Figure 19 shows the laminar flame speed at 1 bar and different temperatures obtained using the molar fraction mixing rule Eq. (5), mass fraction Eq. (6), energy fraction Eq. (7), molar based Le Chatelier's Eq. (9), and energybased Le Chatelier's Eq. (10). The energy-based Le Chatelier's mixing rule is found to be the most accurate at different pressures up to 40 bar over a wide range of equivalence ratios, as shown in Fig. 20.

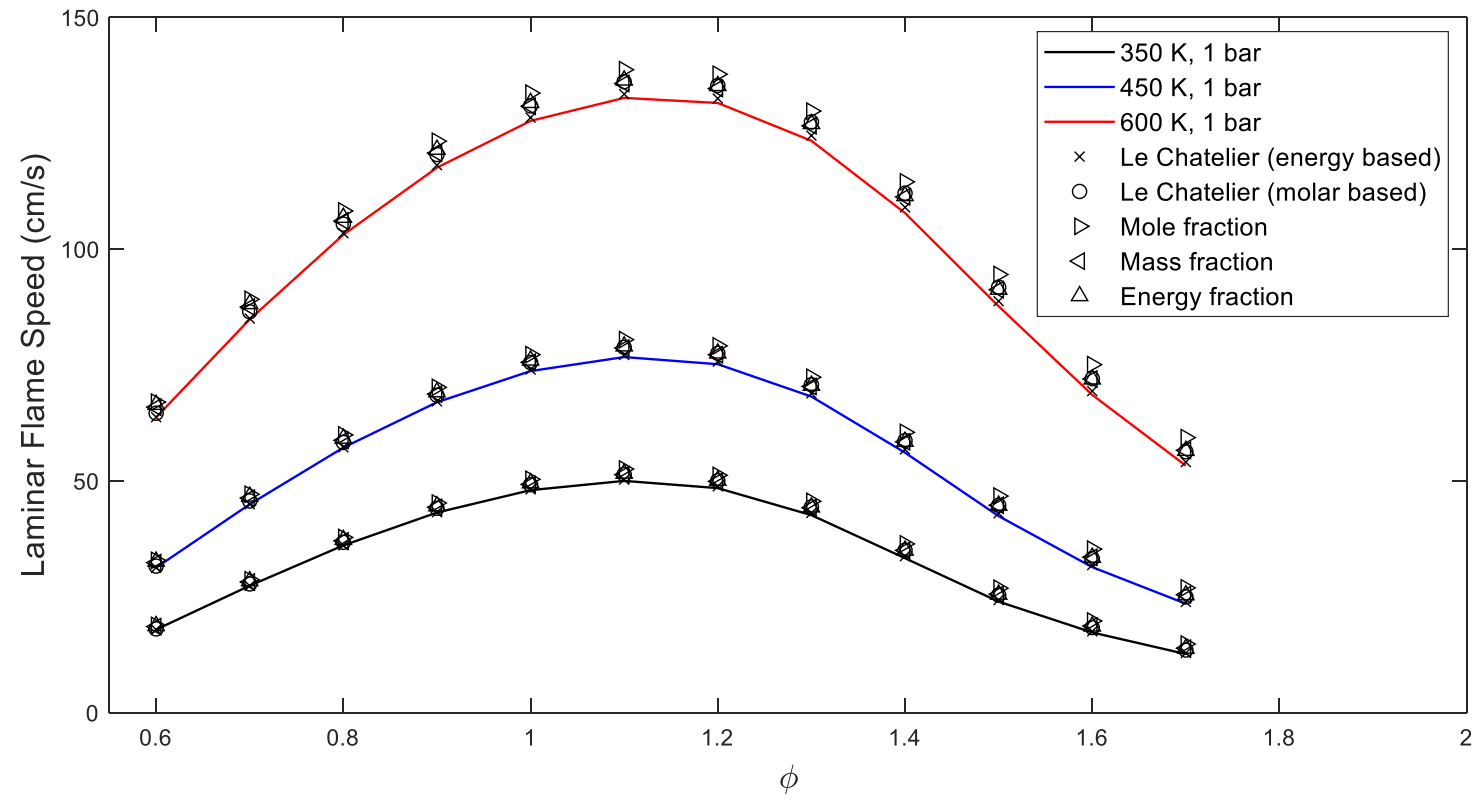

Figure 19: Comparison between the LFS of equimolar mixtures obtained using Chemkin-Pro, and the different mixing rules at 1 bar and different temperatures. 


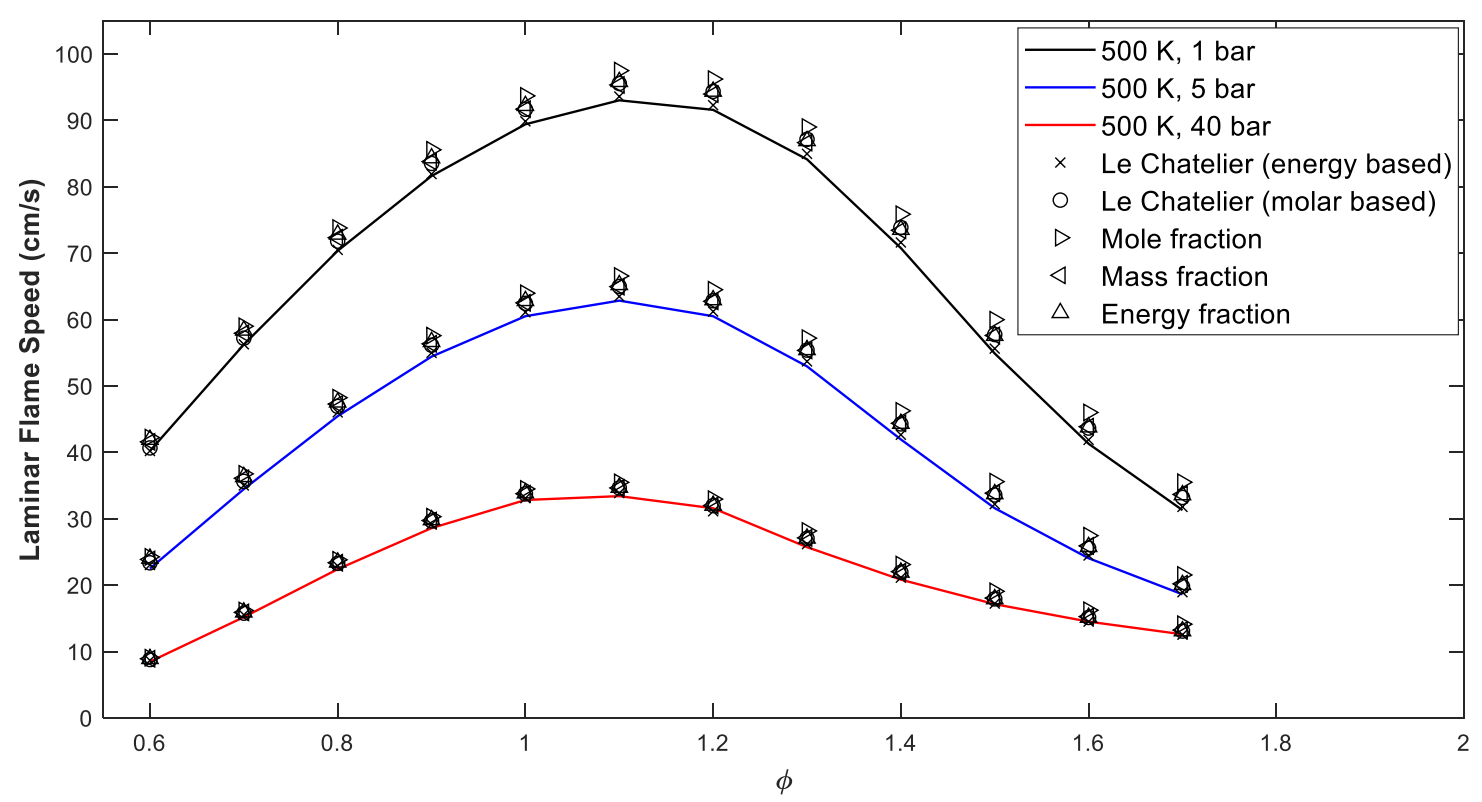

Figure 20: Comparison between the LFS of equimolar mixtures obtained using Chemkin-Pro, and the different mixing rules at $500 \mathrm{~K}$ and different pressures. 


\section{Appendix B: Composition of Random Mixtures}

\section{B.1 Unconstrained Monte-Carlo simulation}

Monte-Carlo simulations are performed for uniformly distributed random mixtures. That can be visually demonstrated for a maximum of three components, as shown previously in Fig. 6. However, we can visualize the uniform randomly generated mixtures of 21 components by comparing the probability density function of each individual component, as can be seen in Fig. 21. We notice that each component experiences random mole fractions similar to the other components.

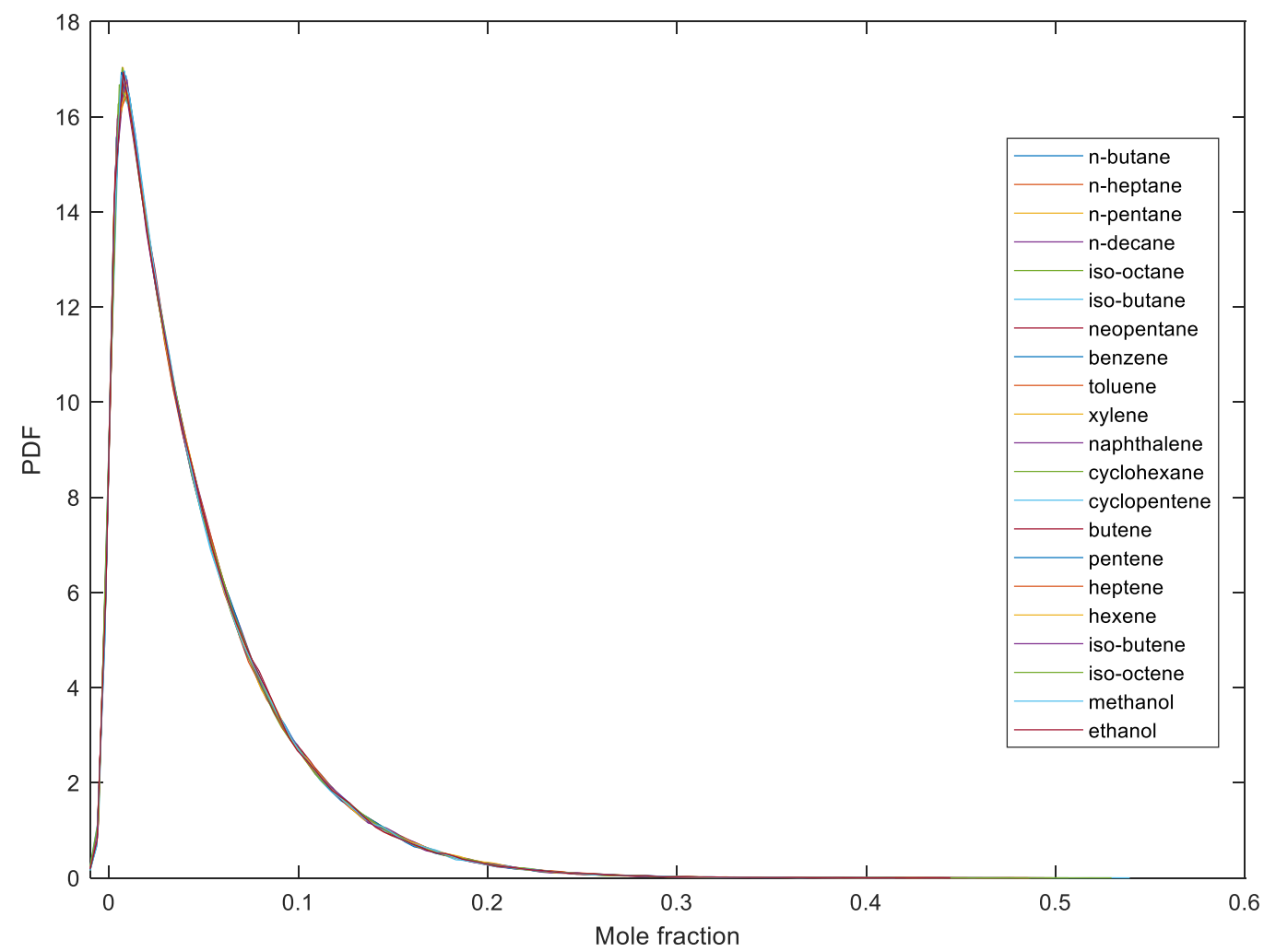

Figure 21: Mole fraction PDFs of each component for 1000 random mixtures. 


\section{B.2 Constrained Monte-Carlo simulation}

Constraints are imposed on Mote-Carlo simulation for better laminar flame speed prediction ability. The aromatics group is constrained to be higher than $30 \%$ while toluene is set to be the dominant component, as shown in Fig. 22. Naphthalene and xylenes are treated equally, and they can be considered as representatives of other large aromatics. The alkenes group is restricted to be less than $6 \%$ while each alkene component is treated equally, as shown in Fig. 23.
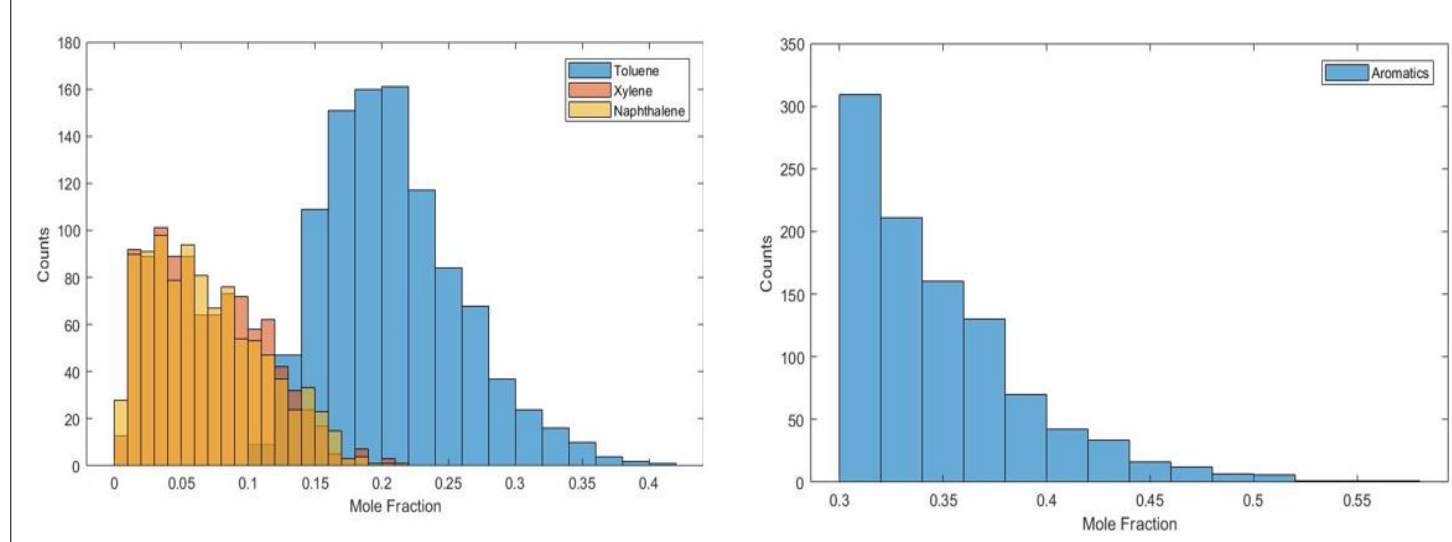

Figure 22: Constrained aromatics group to be higher than $30 \mathrm{~mol} \%$.
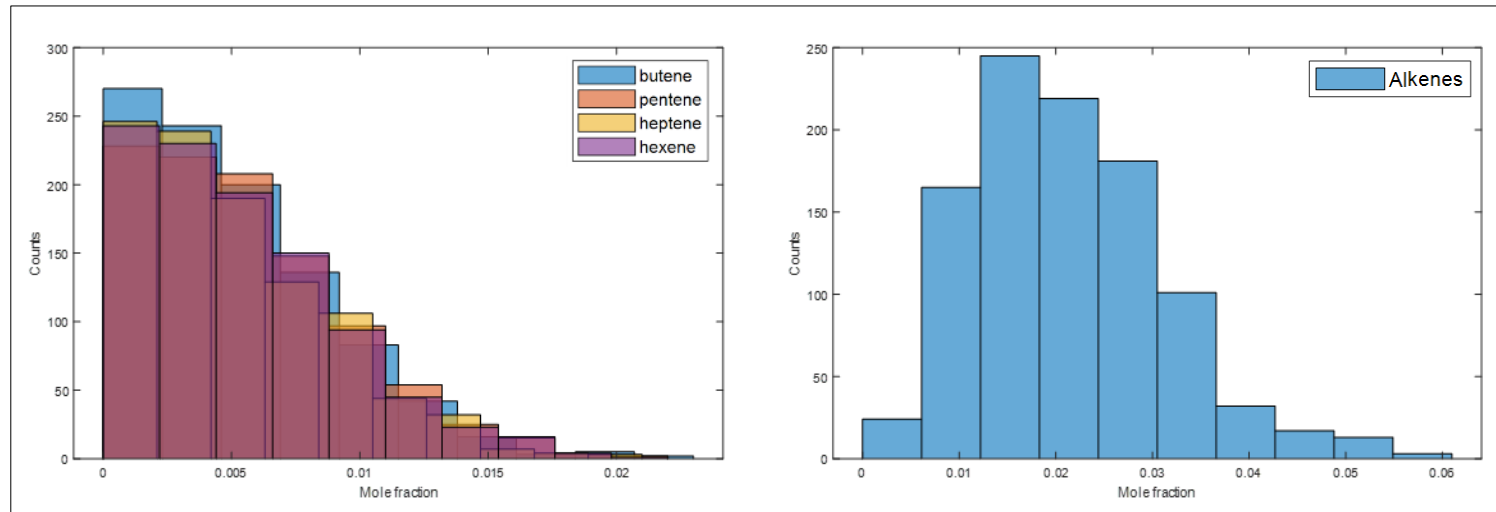

Figure 23: Constrained alkenes group to be less than 6 mol\%. 


\section{B.3 MATLAB code for generating random mixtures}

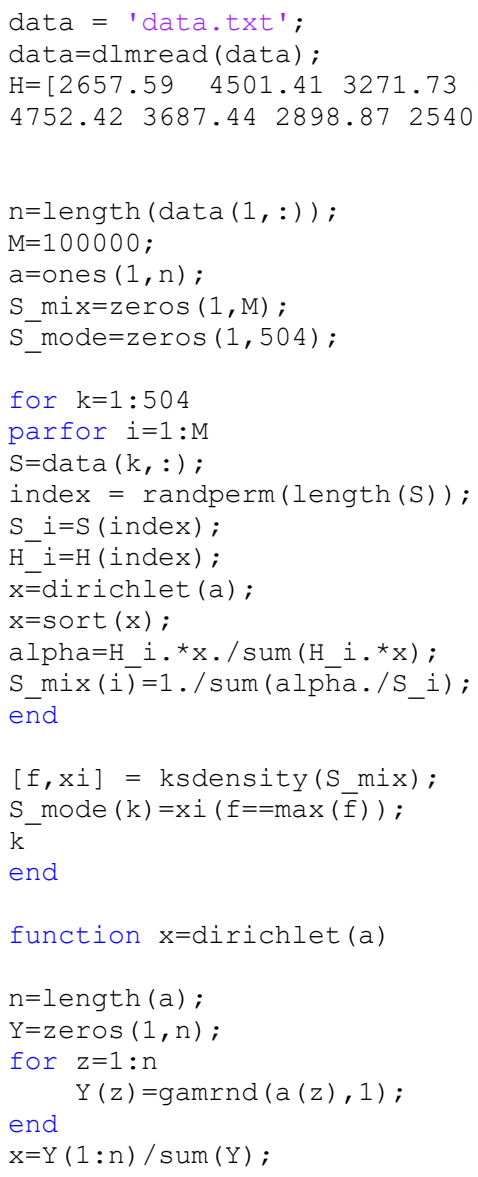




\section{Appendix C: Correlation Formulation}

\section{C.1 Fitting procedure}

Based on the power-law in Eq. (1), the temperature and pressure exponents $\alpha$ and $\beta$ are linear at each equivalence ratio. They are extracted by fitting a line in the normalized logarithmic flame speed dependence, as shown in Fig. (24-25). After that, $\alpha$ and $\beta$ are formulated as functions of the equivalence ratio $\phi$ by curve fitting, as seen in Fig. (26-27). The resulted correlation deviates from the expected Monte-Carlo simulation results in Fig. 28. The deviations are mainly caused by the ignored pressure exponent dependence on temperature Fig. 29. Therefore, $\beta$ is formulated as a function of temperature and equivalence ratio by fitting a surface. The correlation results are improved, as shown in Fig. 30.

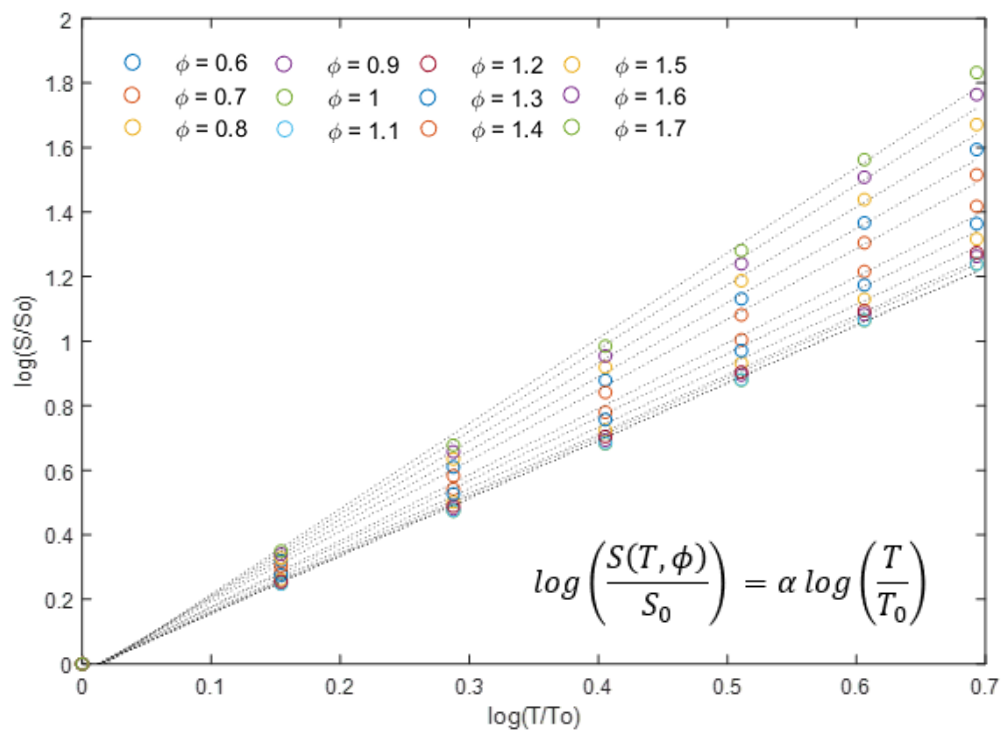

Figure 24: Temperature exponent assuming linear dependence. 


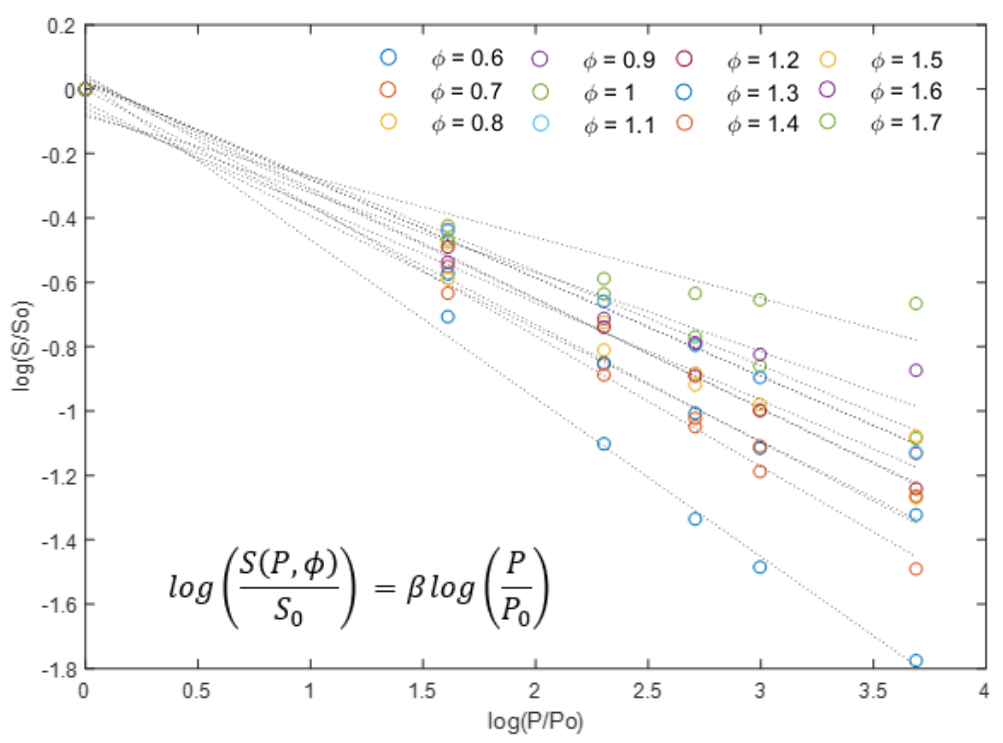

Figure 25: Pressure exponent assuming linear dependence.

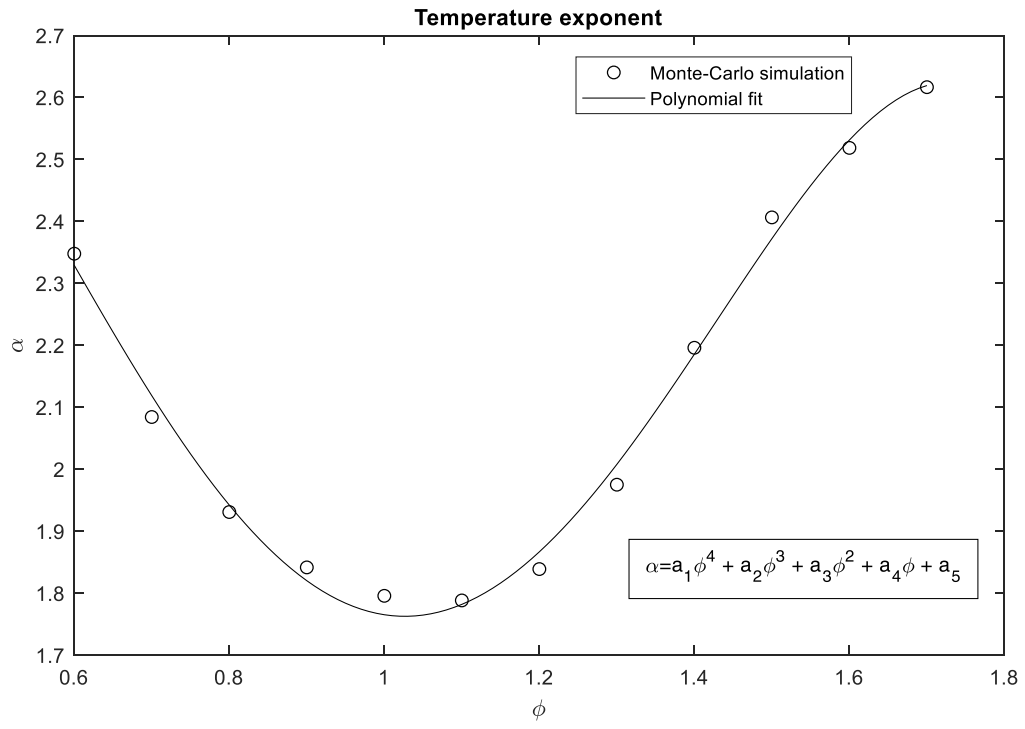

Figure 26: Temperature exponent best fit. 


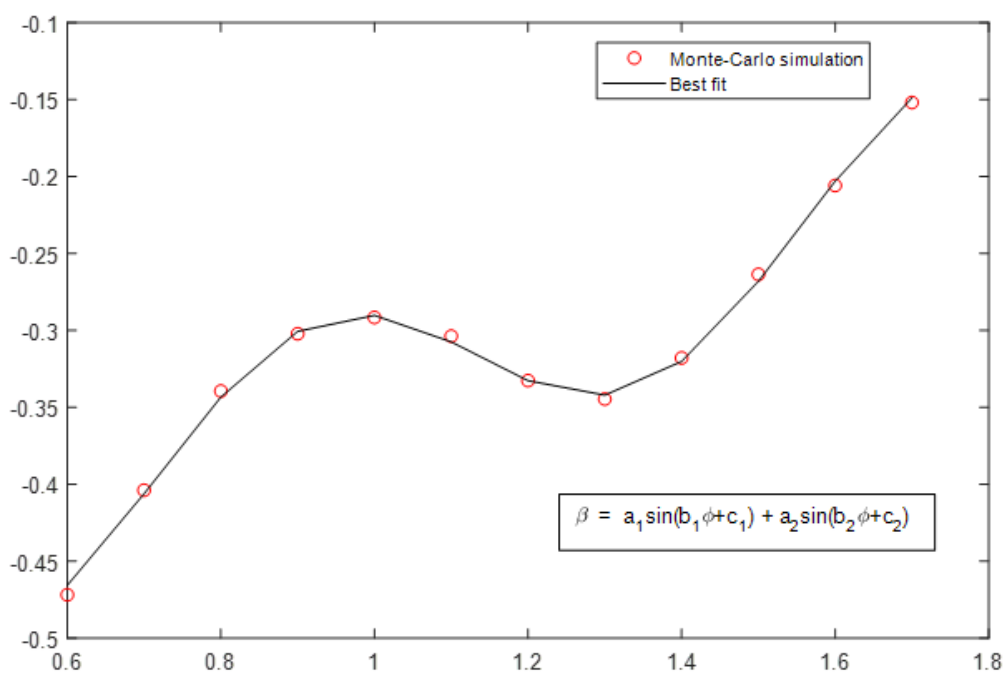

Figure 27: Pressure exponent best fit.

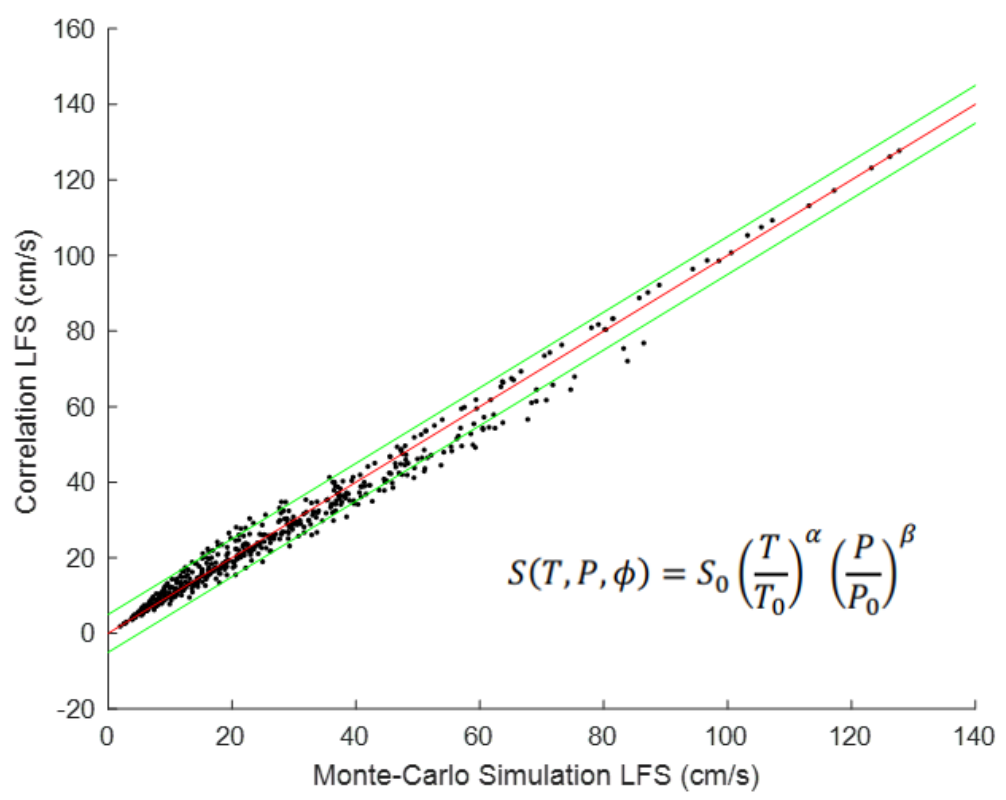

Figure 28: Predicted LFS by Eq. (1) against the expected LFS, green lines are $\pm 5 \mathrm{~cm} / \mathrm{s}$. 


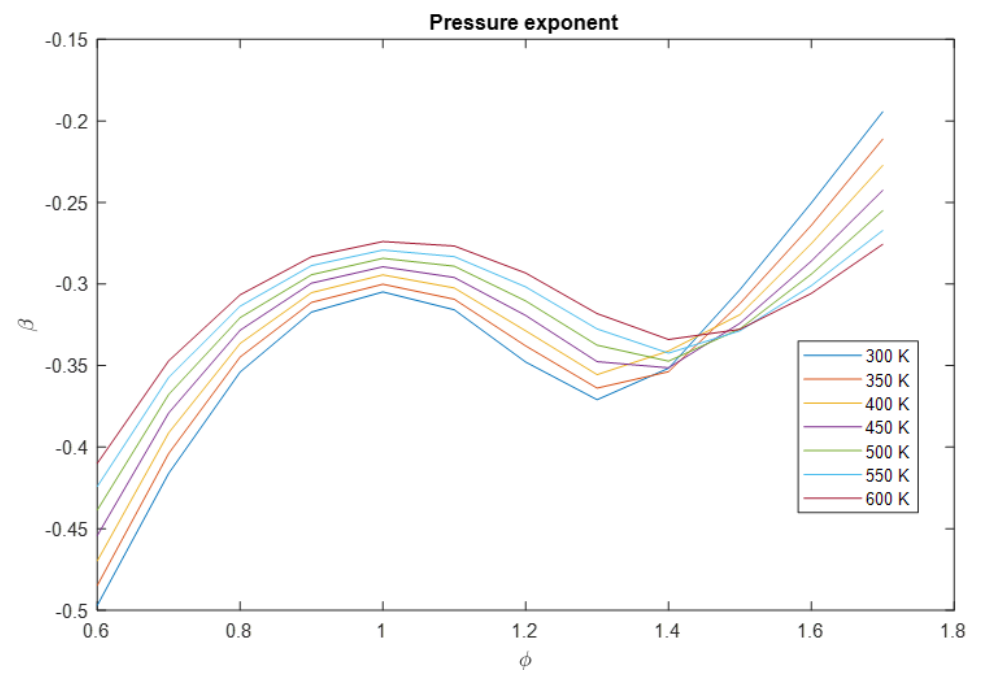

Figure 29: Pressure exponent at different reference temperatures.

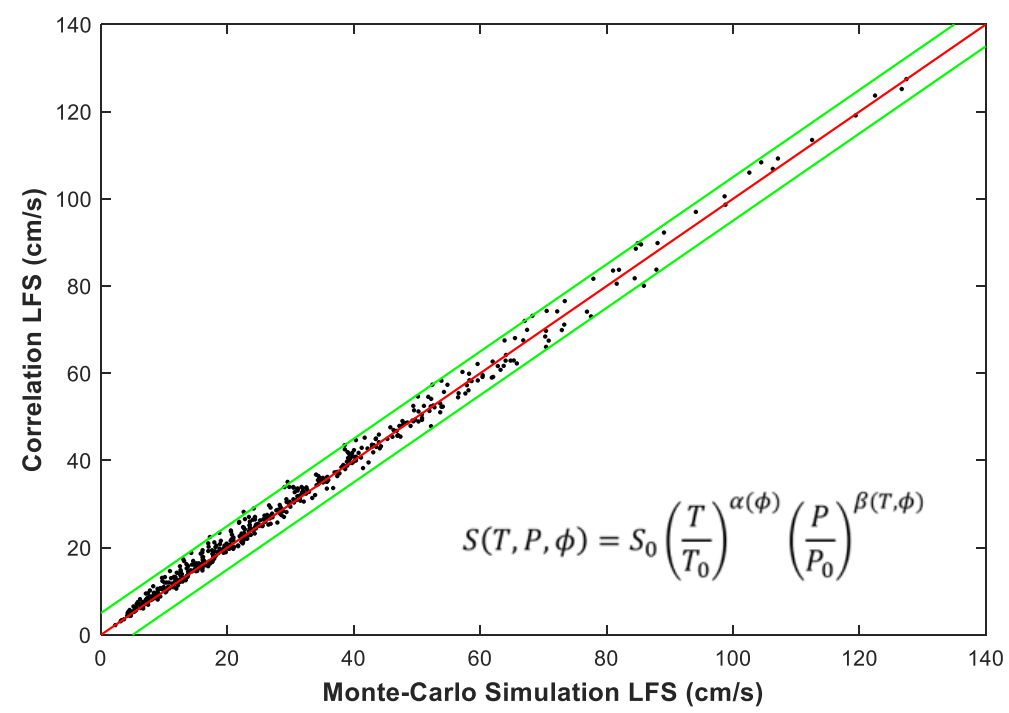

Figure 30: Predicted LFS against the expected LFS, green lines are $\pm 5 \mathrm{~cm} / \mathrm{s}$.

To further enhance the prediction ability, the non-linearity in the pressure and temperature exponents are considered by assuming second-order polynomial dependence, as shown in Fig. (31-32). Then, the best fit is obtained for each of $S_{0}(\phi)$, $\alpha_{1}(\phi), \alpha_{2}(\phi), \beta_{1}(\phi, T)$, and $\beta_{2}(\phi, T)$ as shown the Figures (33-37). The correlation results are mostly within $\pm 2 \mathrm{~cm} / \mathrm{s}$, as shown in Fig. 38 . 


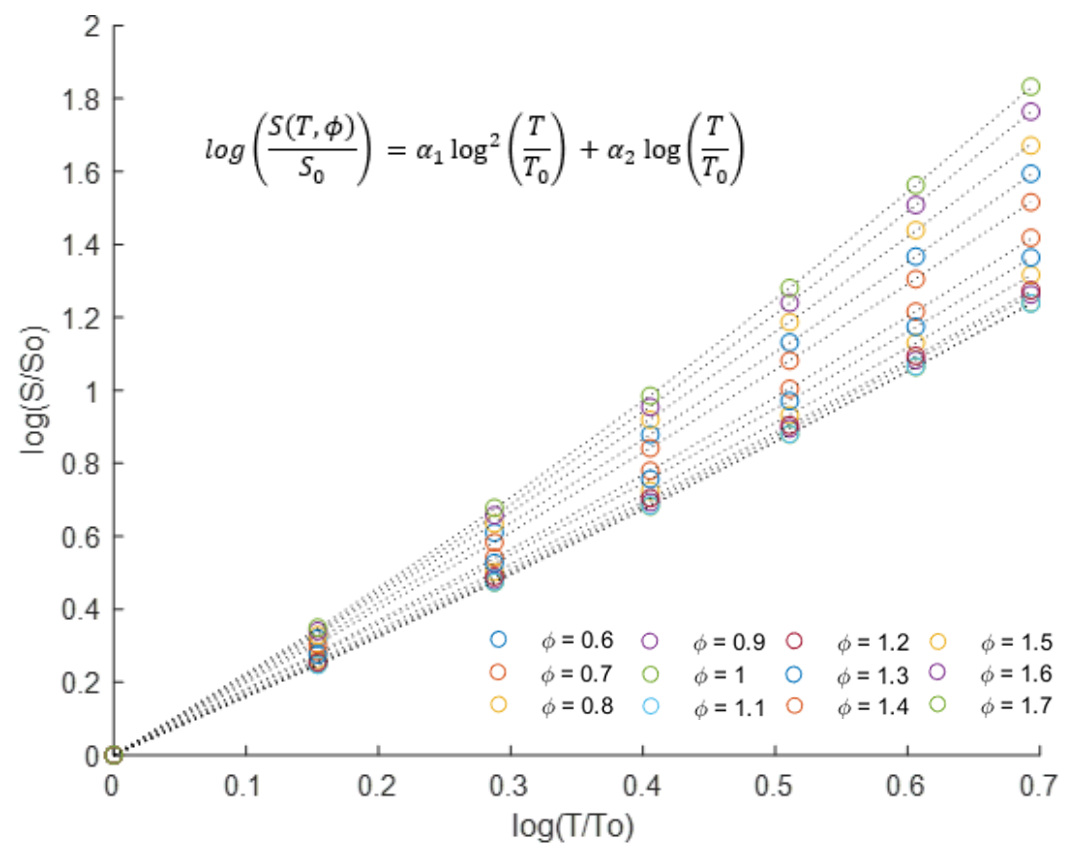

Figure 31: Temperature exponents, assuming non-linear dependence.

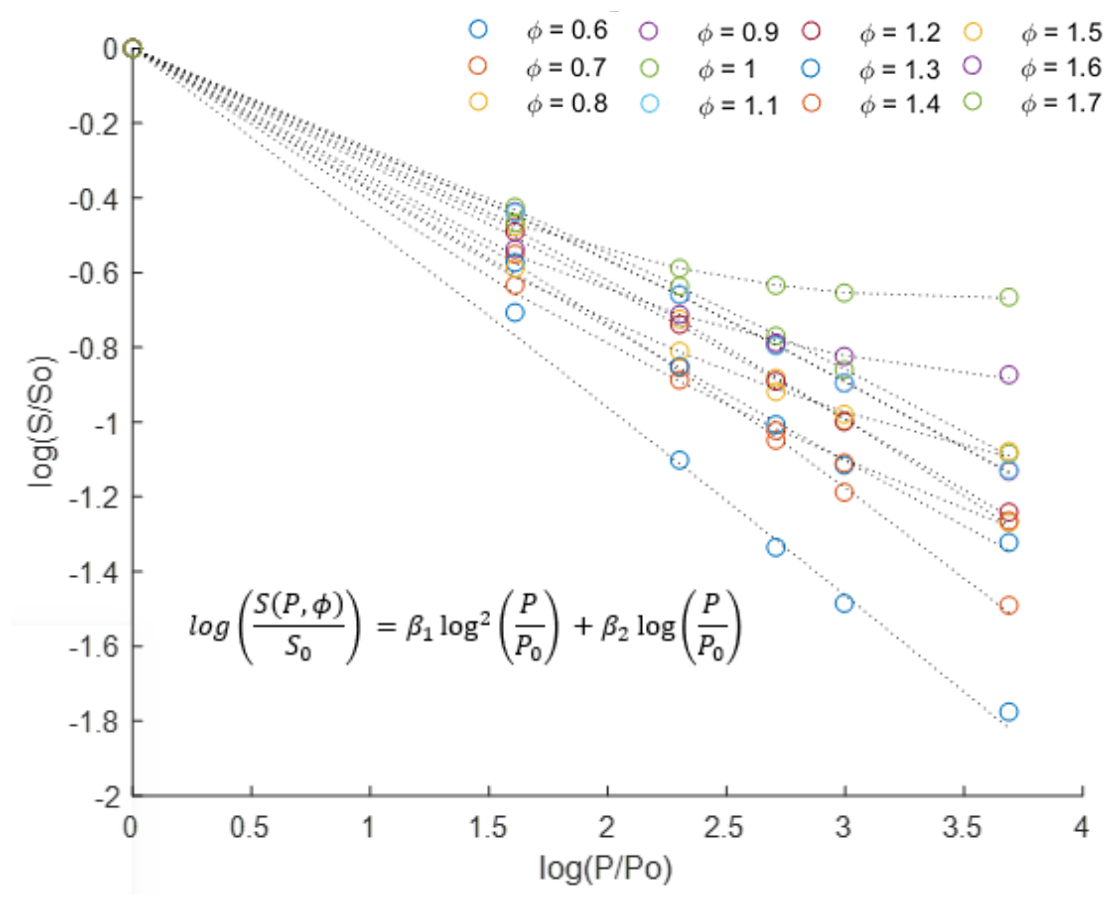

Figure 32: Pressure exponents, assuming non-linear dependence. 


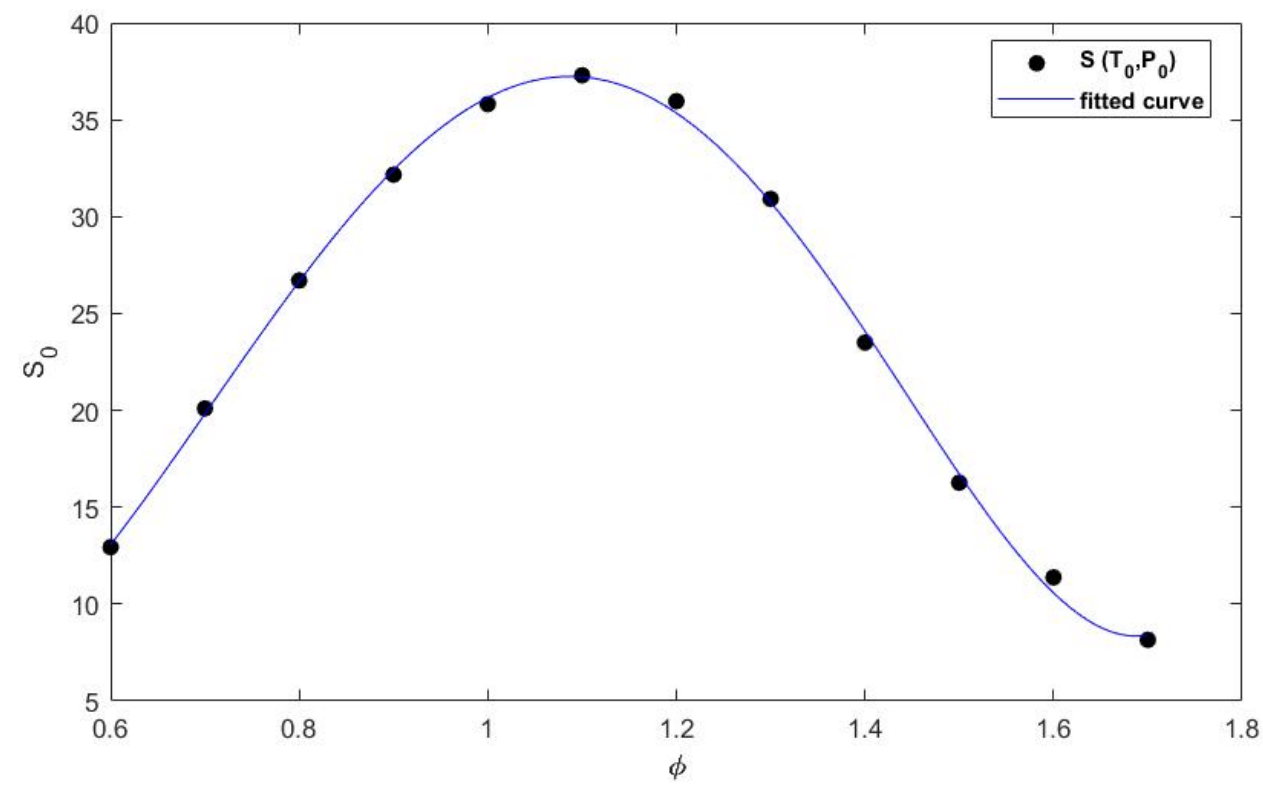

Figure 33: Best fit for the Laminar flame speed at the reference conditions $300 \mathrm{~K}$ and $40 \mathrm{bar} \mathrm{Eq.} \mathrm{(17).}$

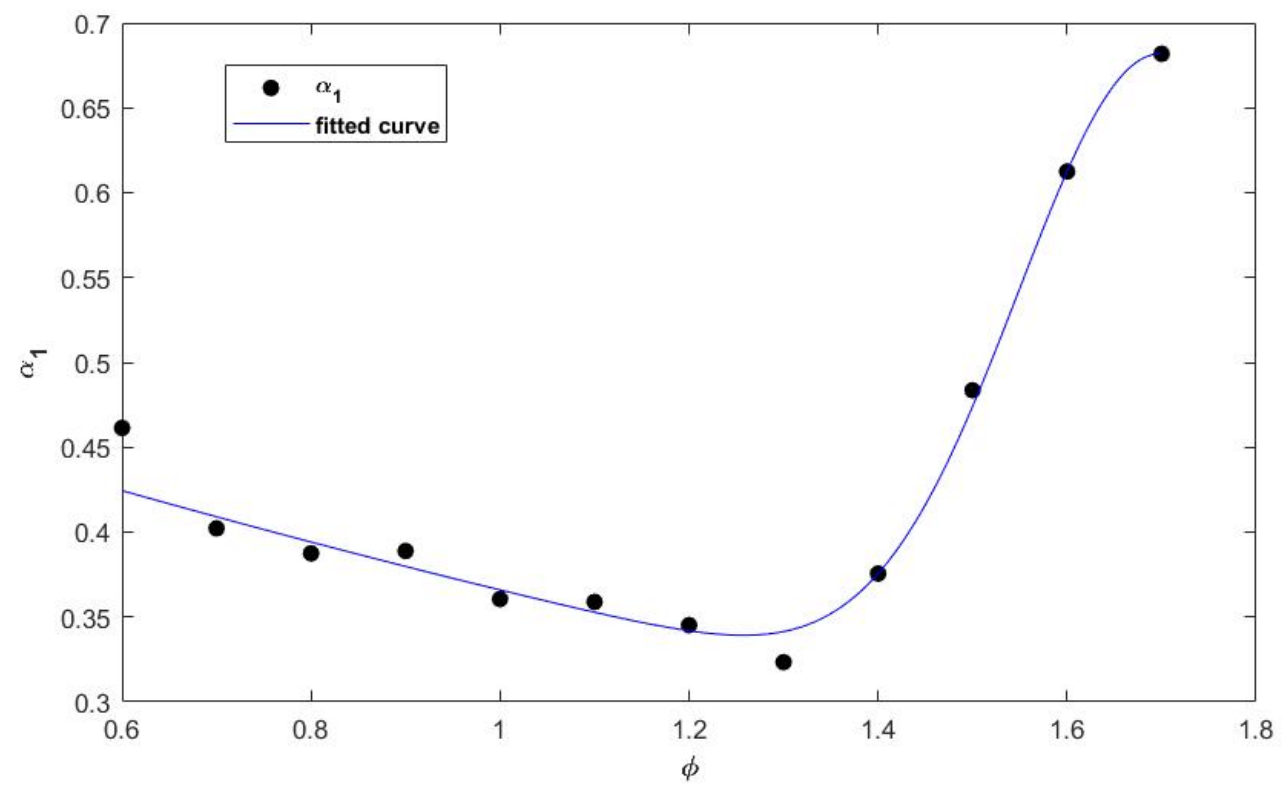

Figure 34: $\alpha_{1}$ best fit Eq. (18). 


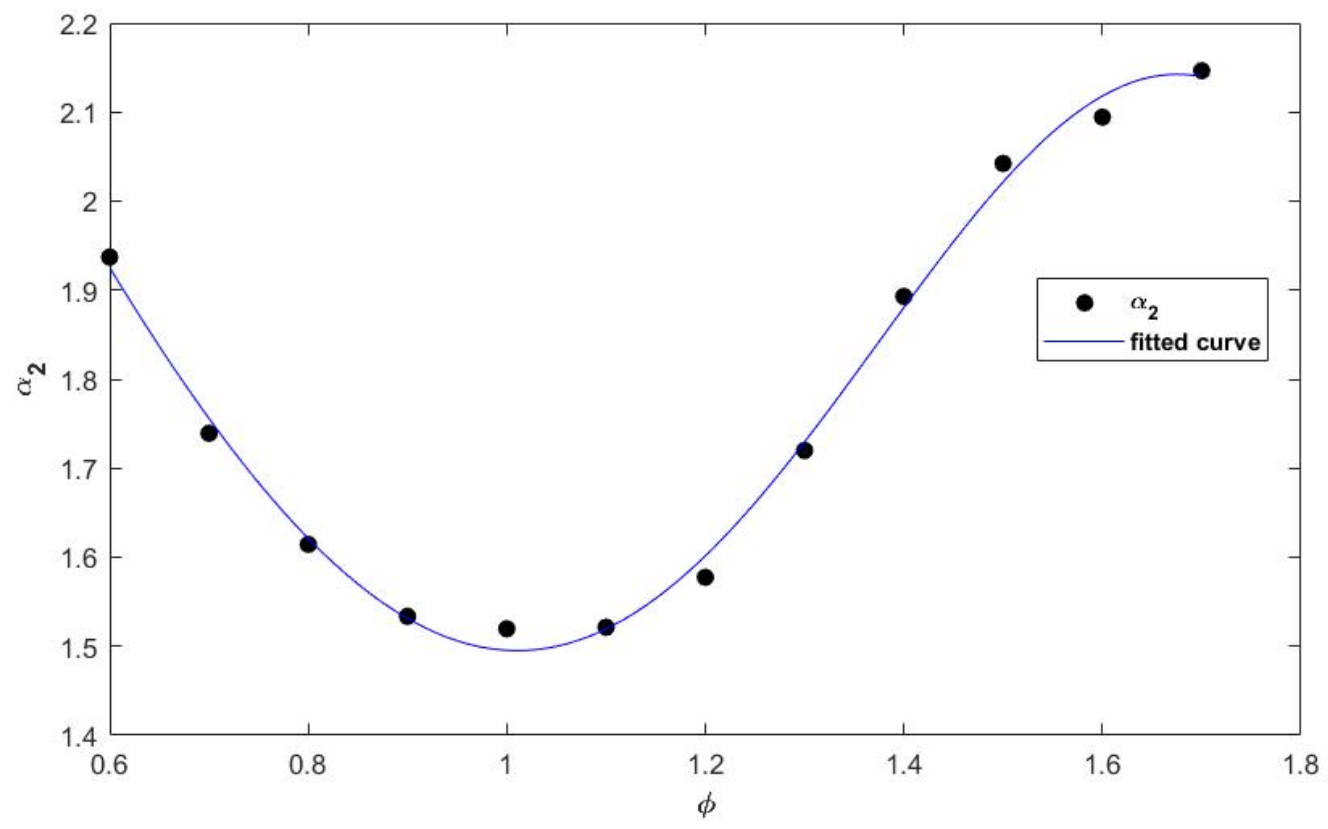

Figure 35: $\alpha_{2}$ best fit Eq. (19).

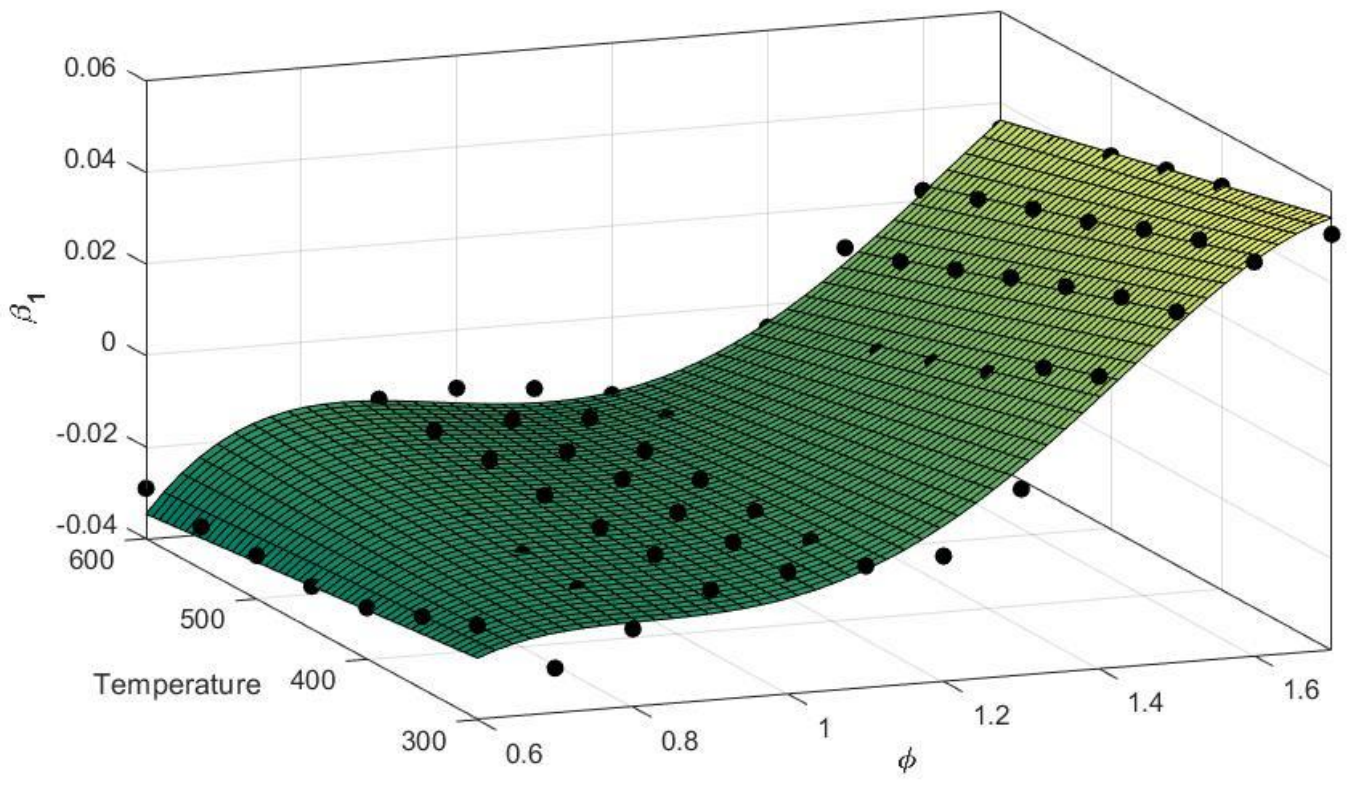

Figure 36: $\beta_{1}$ best fit Eq. (20). 


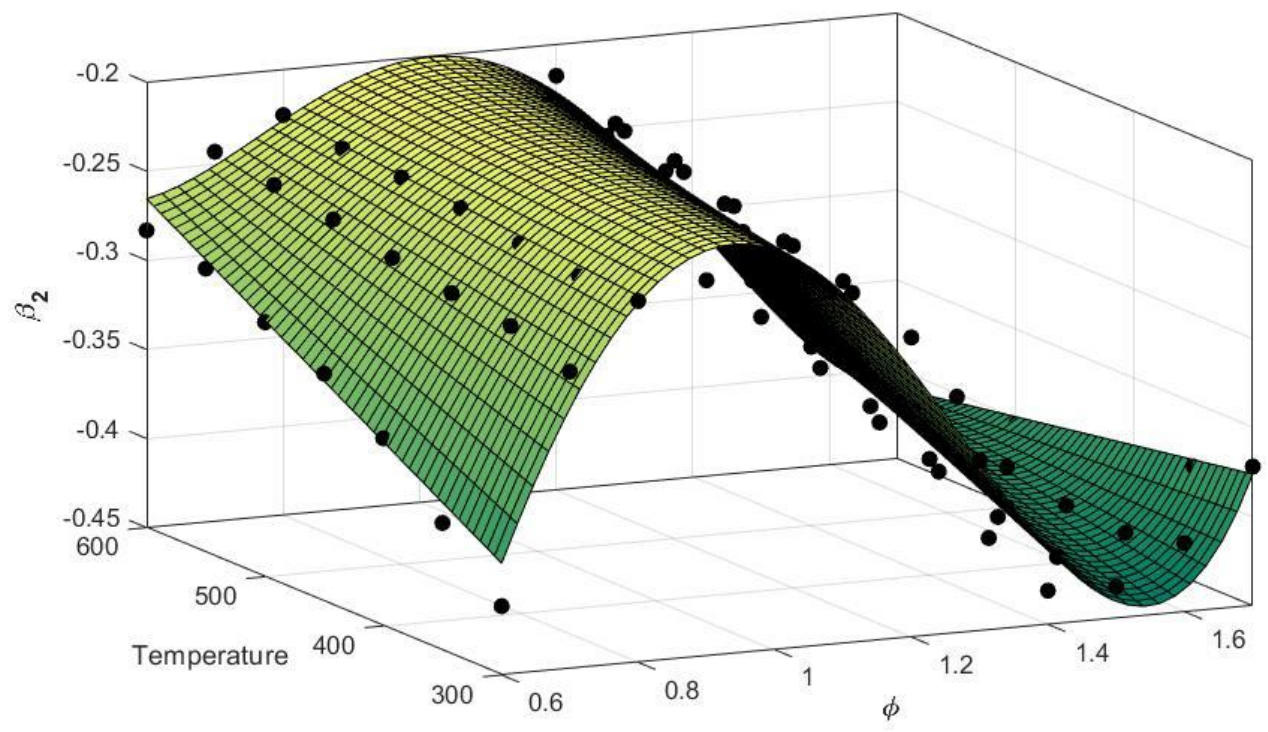

Figure 37: $\beta_{2}$ best fit Eq. (21).

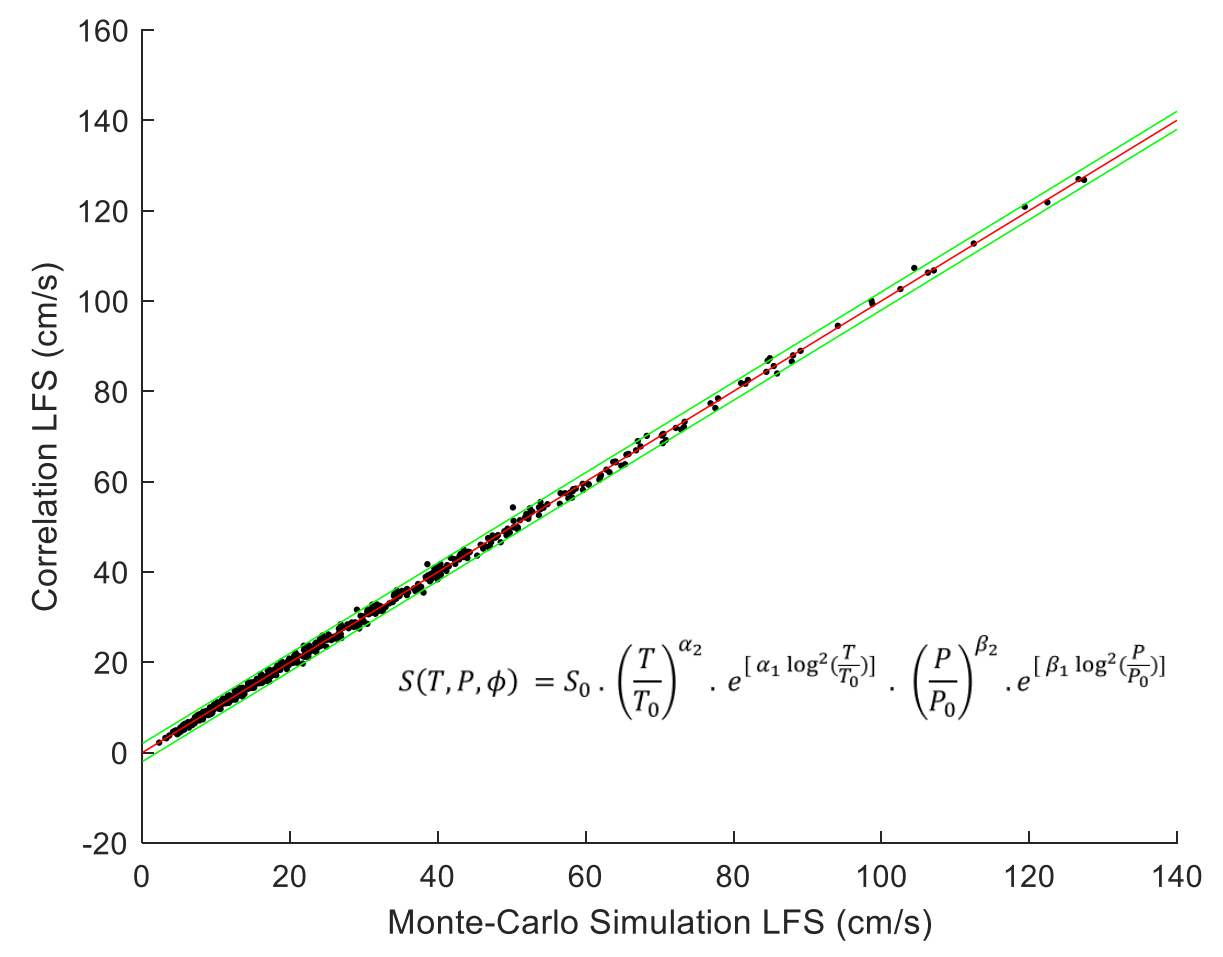

Figure 38: Comparison between the predicted and expected LFS values the green lines are $\pm 2 \mathrm{~cm} / \mathrm{s}$. 
Table 5: Goodness of fit.

\begin{tabular}{l|ccc}
\hline Fit equation & $\mathbf{R}^{\mathbf{2}}$ & $\mathrm{SSE}$ & $\mathrm{RMSE}$ \\
\hline $\boldsymbol{S}_{\mathbf{0}}$ Eq. (17). & 0.9984 & 81.1577 & 0.4037 \\
$\boldsymbol{\alpha}_{\mathbf{1}}$ Eq. (18). & 0.9851 & 0.0854 & 0.0131 \\
$\boldsymbol{\alpha}_{\mathbf{2}}$ Eq. (19). & 0.9952 & 0.1224 & 0.0157 \\
$\boldsymbol{\beta}_{\mathbf{1}}$ Eq. (20). & 0.9778 & 0.0063 & 0.0036 \\
$\boldsymbol{\beta}_{\mathbf{2}}$ Eq. (21). & 0.9775 & 0.0645 & 0.0114 \\
\hline
\end{tabular}




\section{C.2 MATLAB code for calculating $\alpha_{1}, \alpha_{2}, \beta_{1}$, and $\beta_{2}$}

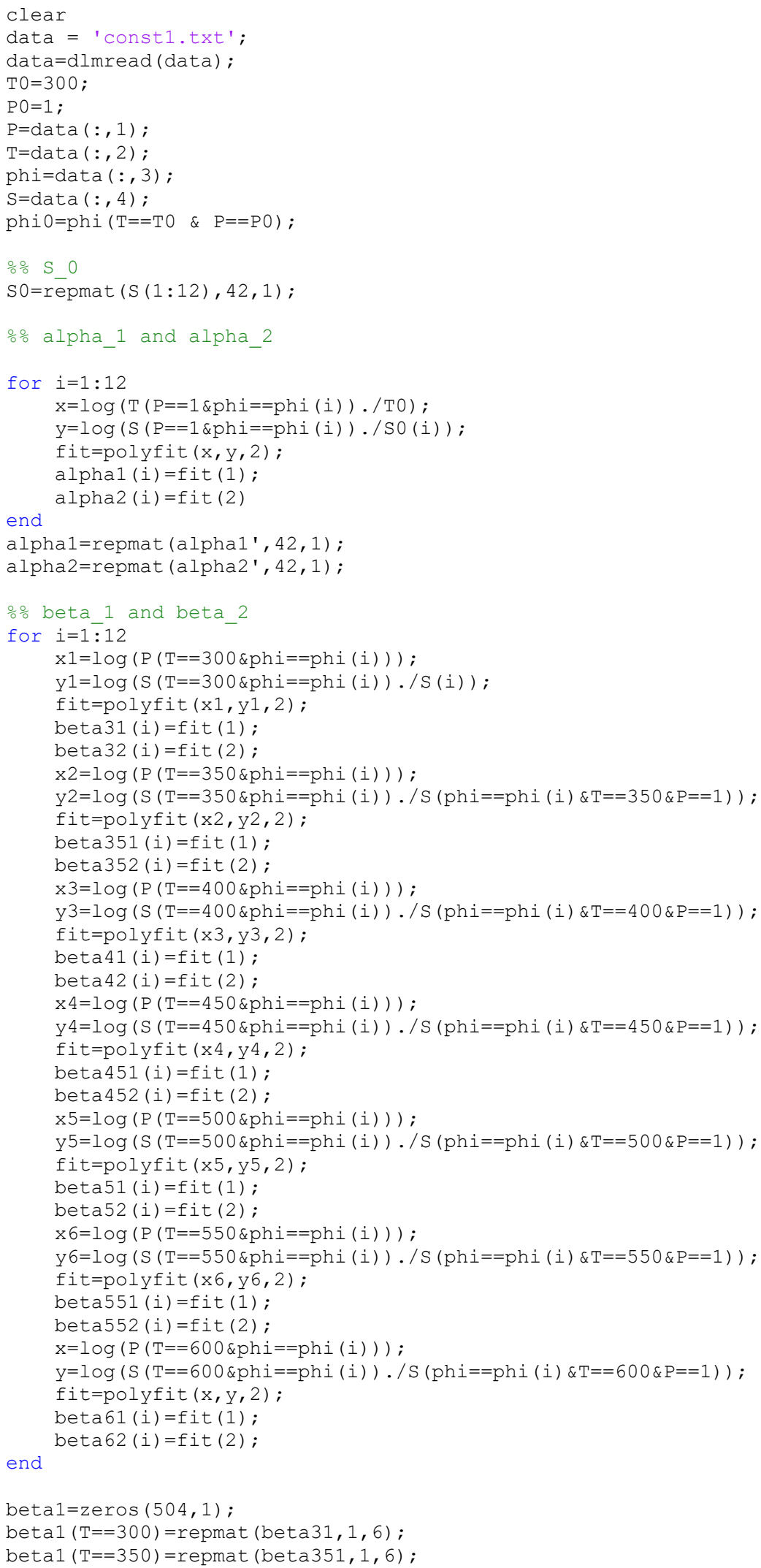


betal $(\mathrm{T}==400)=\operatorname{repmat}(\operatorname{beta} 41,1,6)$; betal $(\mathrm{T}==450)=\operatorname{repmat}(\operatorname{beta} 451,1,6)$; betal $(\mathrm{T}==500)=\operatorname{repmat}($ beta $51,1,6)$; betal $(\mathrm{T}==550)=\operatorname{repmat}($ beta551, 1,6$)$; beta1 $(\mathrm{T}==600)=\operatorname{repmat}($ beta $61,1,6)$;

beta $2=\operatorname{zeros}(504,1)$;

beta2 $(\mathrm{T}==300)=\operatorname{repmat}($ beta $32,1,6)$;

beta2 $(\mathrm{T}==350)=\operatorname{repmat}(\operatorname{beta} 352,1,6)$;

beta2 $(\mathrm{T}==400)=\operatorname{repmat}($ beta $42,1,6)$;

beta $2(\mathrm{~T}==450)=\operatorname{repmat}($ beta $452,1,6)$;

beta2 $(\mathrm{T}==500)=\operatorname{repmat}($ beta52, 1,6$)$;

beta2 $(\mathrm{T}==550)=\operatorname{repmat}($ beta552, 1,6$)$;

beta2 $(\mathrm{T}==600)=\operatorname{repmat}($ beta62, 1,6); 


\section{C.3 MATLAB code for the correlation}

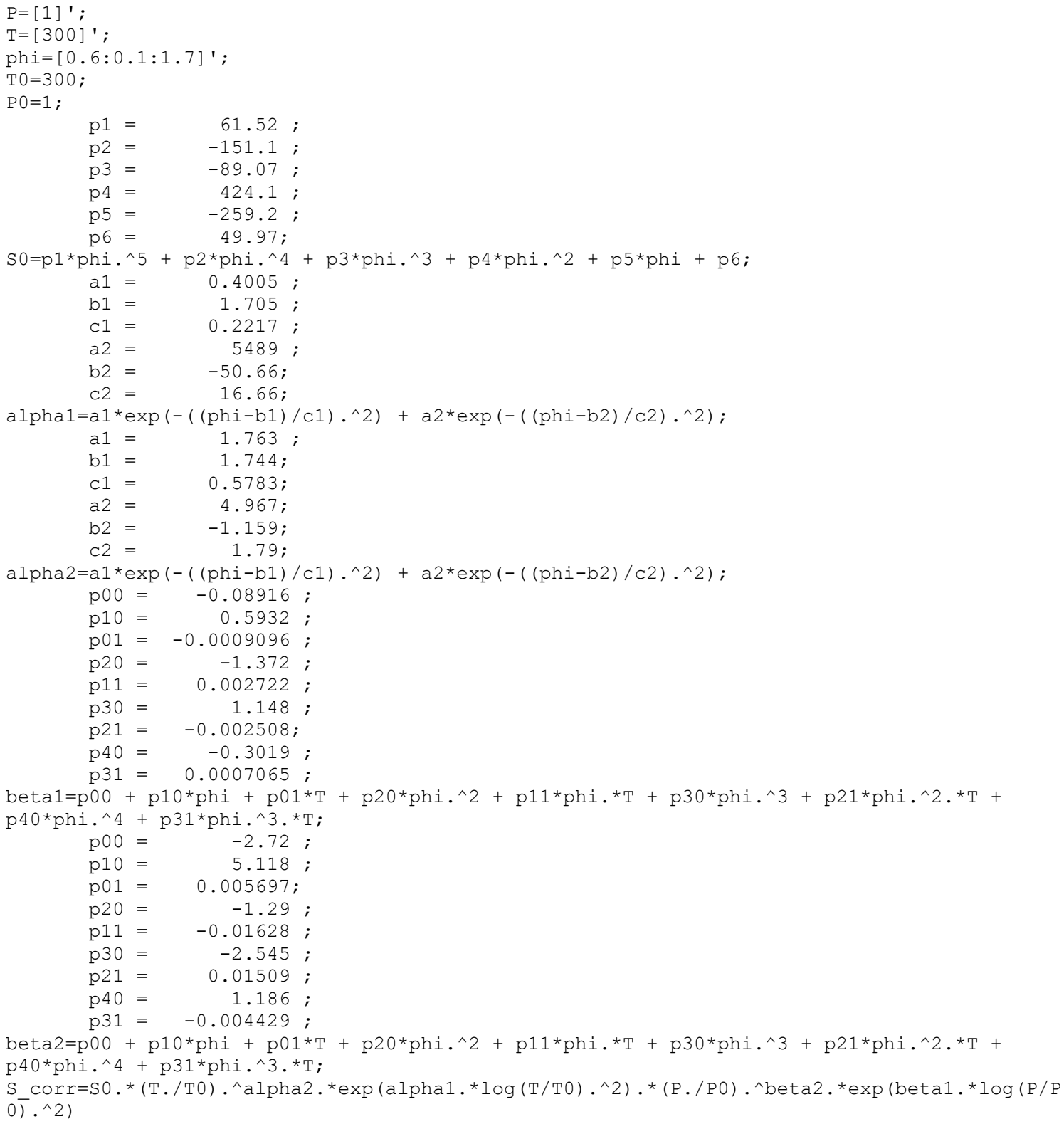

